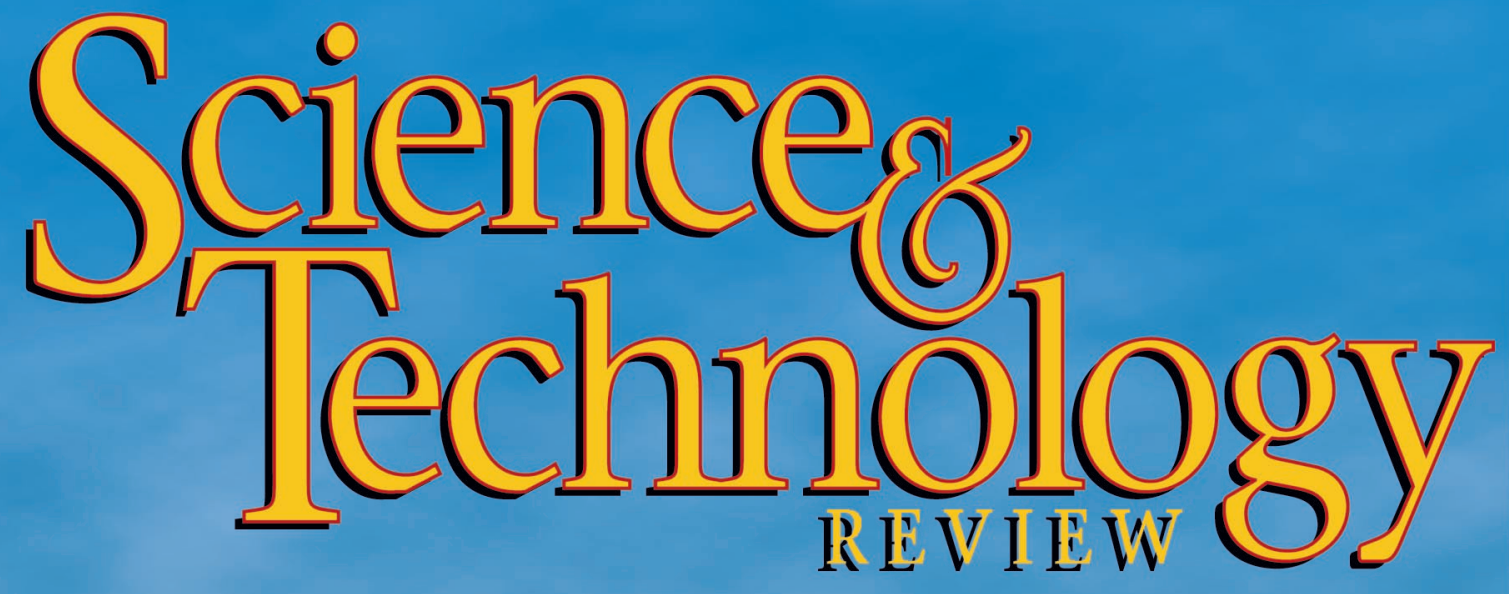

July/August 2004

National Nuclear

Security Administration's Lawrence Livermore National Laboratory

\title{
Innovative Technologies
} to Protect Water Supplies -

Also in this issue:

- Chemistry at Extreme Pressures and Tenperatures

- A Selj-Contajned, Portable Reactor

- Jyeasuring a Shock Wave's Velocity

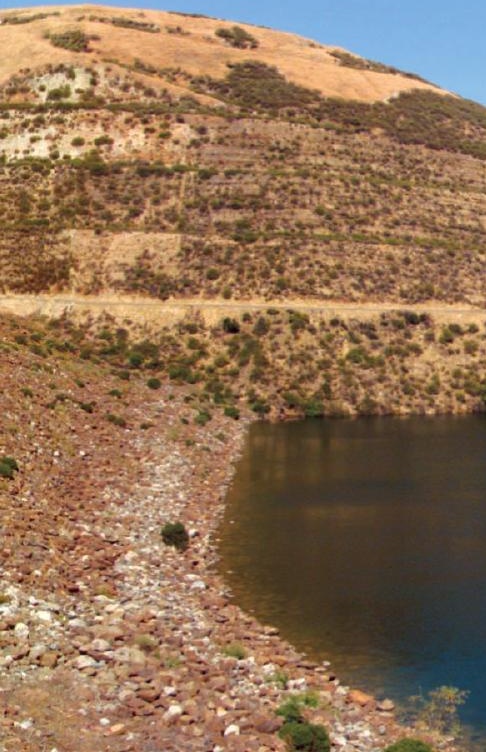




\section{About the Cover}

Ensuring plentiful water supplies is becoming a critical issue in California. The state's underground aquifers are being consumed at an increasing rate, and contaminants and climate patterns may affect the adequacy of supplies. As described in the article beginning on $\mathrm{p} .4$, a team of Laboratory scientists is pursuing a three-year initiative to address these challenges by developing tools to evaluate the state's water-supply infrastructure, protection and purification efforts, and flood control. The cover shows two components of California's intricate system. The Del Valle Reservoir near Livermore is one of many reservoirs used to store water. Melting snow from the Sierra Nevada feeds the state's reservoirs and rivers during the spring and summer.

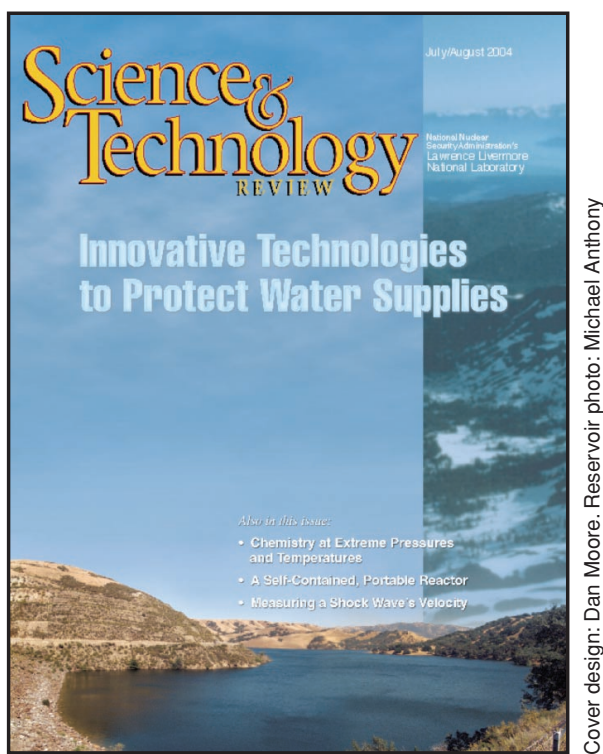

\section{About the Review}

Lawrence Livermore National Laboratory is operated by the University of California for the Department of Energy's National Nuclear Security Administration. At Livermore, we focus science and technology on assuring our nation's security. We also apply that expertise to solve other important national problems in energy, bioscience, and the environment. Science \& Technology Review is published 10 times a year to communicate, to a broad audience, the Laboratory's scientific and technological accomplishments in fulfilling its primary missions. The publication's goal is to help readers understand these accomplishments and appreciate their value to the individual citizen, the nation, and the world.

Please address any correspondence (including name and address changes) to $S \& T R$, Mail Stop L-664, Lawrence Livermore National Laboratory, P.O. Box 808, Livermore, California 94551, or telephone (925) 423-3432. Our e-mail address is str-mail@1lnl.gov. S\&TR is available on the World Wide Web at www.llnl.gov/str.

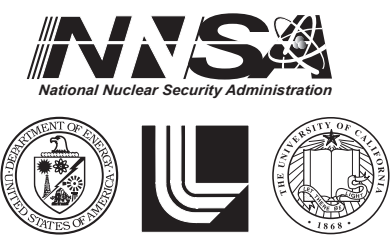

Prepared by LLNL under contract No. W-7405-Eng-48
(C) 2004. The Regents of the University of California. All rights reserved. This document has been authored by the Regents of the University of California under contract No. W-7405-Eng-48 with the U.S. Government. To request permission to use any material contained in this document, please submit your request in writing to the Business Services Department, Information Management Group, Lawrence Livermore National Laboratory, Mail Stop L-664, P.O. Box 808, Livermore, California 94551, or to our electronic mail address report-orders@1lnl.gov.

This document was prepared as an account of work sponsored by an agency of the United States Government. Neither the United States Government nor the University of California nor any of their employees makes any warranty, expressed or implied, or assumes any legal liability or responsibility for the accuracy, completeness, or usefulness of any information, apparatus, product, or process disclosed, or represents that its use would not infringe privately owned rights. Reference herein to any specific commercial product, process, or service by trade name, trademark, manufacturer, or otherwise, does not necessarily constitute or imply its endorsement, recommendation, or favoring by the United States Government or the University of California. The views and opinions of authors expressed herein do not necessarily state or reflect those of the United States Government or the University of California and shall not be used for advertising or product endorsement purposes. 


\section{Sciences Technology

\section{S\&TR Staff}

\section{Scientific Editor}

Van Emden Henson

\section{Managing Editor}

Ray Marazzi

\section{Publication Editor}

Carolin Middleton

\section{Writers}

Arnie Heller, Ann Parker,

Gabriele Rennie, and

Maurina S. Sherman

Art Director and Designer

Dan Moore

\section{Compositor}

Louisa Cardoza

\section{Proofreader}

Karen Rath

$S \& T R$, a Director's Office publication, is produced by the Technical Information Department under the direction of the Office of Policy, Planning, and Special Studies.

$S \& T R$ is available on the Web at www.llnl.gov/str.

Printed in the United States of America

\section{Available from}

National Technical Information Service

U.S. Department of Commerce

5285 Port Royal Road

Springfield, Virginia 22161

\section{UCRL-TR-52000-04-7/8}

Distribution Category UC-99

July/August 2004

\section{Contents}

\section{Features}

3 Technologies to Address California's Water-Supply Challenge Commentary by C. K. Chou

4 Helping Water Managers Ensure Clean and Reliable Supplies Livermore researchers are developing technologies to better manage California's precious water resources.

\section{Going to Extremes}

Laboratory researchers are studying materials under intense pressures and temperatures to understand chemical reactions at extreme conditions.

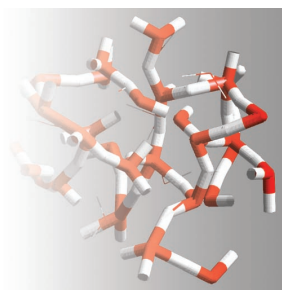

\section{Research Highlights}

20 Nuclear Energy to Go: A Self-Contained, Portable Reactor Researchers are designing a self-contained, tamper-resistant nuclear reactor that can be transported and installed anywhere in the world.

\section{This Instrument Keeps the Beat}

A new instrument uses telecommunications equipment and the beat frequency to track extreme velocities.

\section{Departments}

2 The Laboratory in the News

26 Patents and Awards

\section{Abstracts}




\section{Distant pollution sources affect cloud formations}

A team of researchers, including Livermore computer scientist David Stevens, has determined a close tie between distant sources of pollution and the formation of clouds that influence global climate. The study focused on anvil cirrus clouds, an important but poorly understood element of Earth's climate system.

In this study, researchers used data from a National Aeronautics and Space Administration (NASA) field experiment called CRYSTAL-FACE (Cirrus Regional Study of Tropical Anvils and Cirrus Layers - Florida Area Cirrus Experiment). The experiment obtained the first comprehensive measurements of aerosols and cloud particles throughout the atmospheric column during the evolution of multiple deep convective storm systems. Detailed cloud simulations that resolve the size distributions of aerosols and cloud particles were then made using the Livermore-developed DHARMA code. The researchers found that most anvil ice crystals form on midtropospheric aerosols - that is, on aerosols 6 to 10 kilometers above Earth's surface. Scientists previously assumed that the aerosols needed for cloud formation are suspended closer to Earth's surface.

This project was led by researchers from NASA's Ames Research Center and included collaborators from the National Center for Atmospheric Research, University of North Dakota, Hampton University, Universidad Nacional Autónoma de Mexico, Stratton Park Engineering Company Inc., University of Denver, California Institute of Technology, and Center for Interdisciplinary Remotely-Piloted Aircraft Studies. The team's findings were published in the April 30, 2004, issue of Science.

Contact: David Stevens (925) 422-7649 (dstevens@IInl.gov).

\section{Gene-rich human chromosome-19 sequence completed}

In the April 1, 2004, issue of Nature, a team of investigators, including researchers from Lawrence Livermore and Los Alamos national laboratories, described the completed sequencing of human chromosome 19, the most gene-rich of all the human chromosomes. The project is part of a long-term collaboration led by the Department of Energy's (DOE's) Joint Genome Institute (JGI) and the Human Genome Center at Stanford University and included researchers from the University of California at Santa Cruz; Children's Hospital and Research Center in Oakland, California; the Howard Hughes Medical Institute at the University of Washington, Seattle; Case Western Reserve University; and the National Cancer Institute.

Although chromosome 19 represents only about 2 percent of the human genome, it has 55.8 million bases, or letters, of genetic code and features nearly 1,500 genes. Embedded in the completed sequence data are critical regulatory networks of genes tasked with controlling such functions as repairing DNA damage caused by exposure to radiation and to other environmental pollutants.
DOE originally selected chromosome 19 as a sequencing target to investigate the link between DNA damage from radiation exposure and human cancer. Livermore's initial work, conducted in the mid-1990s, led to mapping many of chromosome 19's DNArepair genes. In 1999, DOE transferred the sequencing effort to JGI and the finishing effort to Stanford. Finishing is the painstaking process of ensuring that the information is completely contiguous and all ambiguities are resolved.

The estimated error rate of the completed chromosome-19 sequence is less than 1 in 100,000 base pairs, which far exceeds the 1 in 10,000 base-pair error rate established by the International Human Genome Sequencing Consortium. This version of the sequence is thus 500 times better than previous drafts in terms of contiguity and accuracy.

Contact: Susan Lucas (925) 296-5638 (lucas11@IInl.gov).

\section{Counterintelligence effort receives excellent rating}

Livermore's Security Awareness for Employees (SAFE) Program earned an excellent rating from the Department of Energy's (DOE's) Office of Counterintelligence (OCI). It is the first overall excellent rating ever garnered by a DOE National Nuclear Security Administration counterintelligence office in such a thorough inspection.

The SAFE Program underwent an intensive audit by inspectors between March 22 and April 1, 2004. OCI inspectors rated SAFE in 12 areas, including management, operations, and liaison with other Laboratory organizations. The inspection report noted SAFE's significant counterterrorism efforts during the past three years. According to the report, the program's liaisons with other Laboratory organizations are particularly noteworthy, and its work with the Federal Bureau of Investigation is outstanding.

Contact: Terry Turchie (925) 422-6366 (turchie1@IInl.gov).

\section{Thunder achieves record cluster efficiency}

Lawrence Livermore's newest supercomputer, called Thunder, debuted as the world's second fastest supercomputer according to the Top500 list released in June 2004. In benchmark testing, Thunder achieved a sustained performance of 19.94 trillion operations per second (teraops). Its theoretical peak speed is rated at 23 teraops.

Thunder is a Linux cluster that runs an open source software environment called CHAOS (Clustered High Availability Operating System), which was developed by the Laboratory. The cluster has 1,024 nodes, each with four Itanium 2 processors that offer processing speeds up to 1.4 gigahertz. In tests, Thunder achieved a record cluster efficiency of 86.9 percent, an important measurement in cluster scalability. The complete Top500 list is available at $w w w . t o p 500.0 r g$.

Contact: Mark Seager (925) 423-3141 (seager@IInl.gov). 


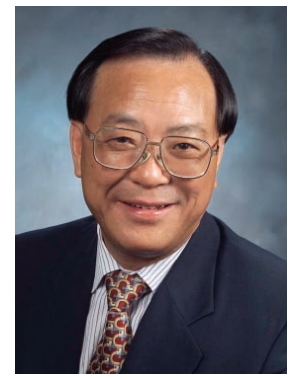

Technologies to Address Califiornia's Water-Supply Challenge

HE growth of California's economy in the 20th century depended on large investments in the state's infrastructure, including major water-supply projects implemented by local, state, and federal agencies. In the 21 st century, the state must continue to address important challenges to ensure that it has the water resources needed to sustain continued economic and population growth.

The 1987-1992 drought prompted aggressive moves by urban water agencies to improve water conservation efforts. After the drought, continued conservation provided much of the water for urban growth during the past decade. With California's population increasing at about 500,000 people per year, the state will need new supplies and storage facilities to maintain the reliability of its water supply - particularly during drought conditions.

Where will California find this "new" water? Part of the supply will undoubtedly come from even better water conservation programs, and agricultural water districts may transfer supplies to urban agencies. Other options include building new dams and conveyance facilities or expanding old ones, reusing wastewater, and desalinating seawater. The state may also decide to increase its reliance on groundwater to meet dry-year demands. Any combination of these options will present environmental consequences that must be addressed.

No matter which choices are made, water agencies will have a more difficult time balancing the increasing demands for water with the available supplies because the state's primary source of freshwater-snowmelt from the Sierra Nevada-may be at risk. Each summer, as the Sierra snowpack gradually melts, the water is stored for distribution throughout California. But hydrologic trend analyses and climate simulations now indicate that this runoff may occur earlier in the spring. Many of the state's reservoirs cannot accumulate supplies from an early spring runoff because floodcontrol regulations limit the amount of water they can store at this time of year. The unfortunate result of this small change in timing is that the overall annual yields from reservoirs may decrease because excess water must be released to avoid flooding.

To make up for the reduced yield of surface reservoirs, California must increase its use of groundwater reservoirs. Although the state has major aquifer systems, many are contaminated with industrial and agricultural chemicals. For example, nitrate from domestic and agricultural sources has contaminated thousands of the state's drinking water wells. Other contaminants also threaten groundwater supplies, including the gasoline additive methyl tertiary butyl ether, or MTBE, and perchlorate, an oxidizing agent.

Given these problems, California water agencies may need to consider nontraditional sources: urban wastewaters, impaired groundwater, and seawater. However, with current technologies, the cost to treat these sources will be about two times more than it is for existing water supplies, and competing demands for the required energy will substantially add to the overall cost. Clearly, California's success in the 21 st century depends on developing solutions to these emerging challenges. But unlike past watersupply projects, which relied primarily on engineering expertise for implementation, future solutions will depend on advanced science and technology.

Lawrence Livermore has a significant opportunity to contribute its expertise to this area, as described in the article beginning on p. 4. For example, the Laboratory's advanced climate and hydrologic simulations can be used to predict future climate patterns and how changes to climate may affect water supplies. Until recently, water managers have had only the historic data to help them plan new infrastructure projects, which will operate far into this century. Applying Livermore's ability to measure, characterize, and simulate the complex biogeochemical processes that control groundwater contamination will benefit managers who increasingly rely on groundwater sources. The development of energy-efficient selective separation technologies tailored to remove specific contaminants would constitute a major advance in water treatment. Collectively, these applications will give water agencies the tools they need to meet the increasingly difficult challenges that lie ahead.

C. K. Chou, associate director of Energy and Environment, retired in June 2004. 


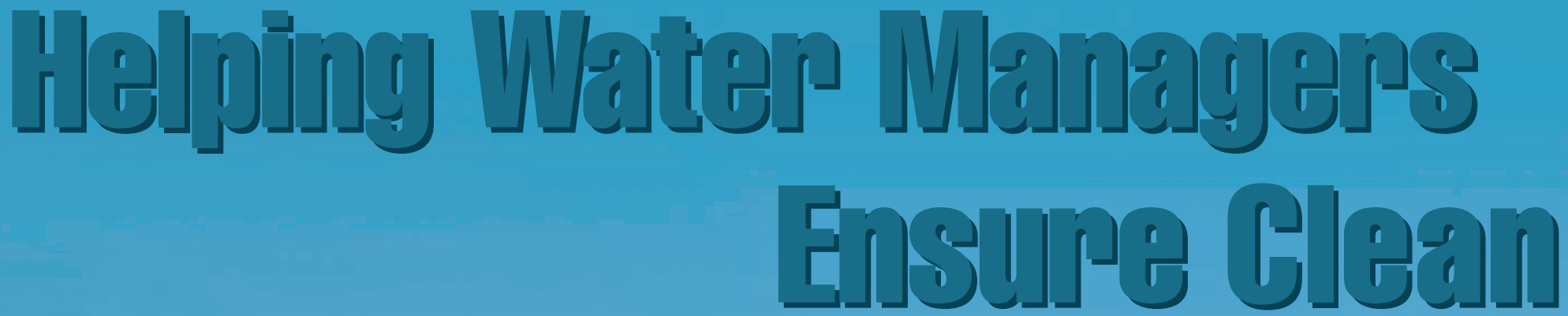

Livermore experts are developing advanced models and new methods to help protect California's

OST Americans take cheap

and plentiful supplies of pure drinking water for granted. Some even consider it to be an inalienable right. However, clean water sources, especially pristine underground aquifers, are being consumed at an increasing rate, and contaminants and changing patterns in rain and snowfall are threatening the adequacy of supplies.

Ensuring plentiful water supplies is becoming a critical issue in California, ye rososires

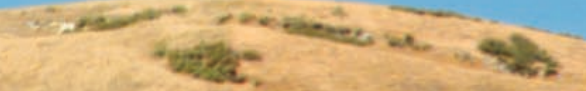

which uses 10 percent of the nation's freshwater. State water managers are closing many contaminated or impaired drinking wells; Sierra snowpacks have diminished in recent years; and the state's farmers, fishermen, environmentalists, and city dwellers cannot always agree on the best uses for a limited supply.

California is not alone with respect to these issues. They are relevant throughout the western U.S. and are becoming more so in other parts of the country. They also are critically important in highly populated and developing nations such as

. 
4 percent of electricity is used to pump, process, and treat water.

The demands for both energy and water are expected to grow substantially in the next 25 years. "As a result," says Newmark, "a strong federal role is needed to provide scientific research, technology development, and analysis capabilities so the nation can achieve energy and water security and sustainability."

\section{Simulations Guide Decision Makers}

In California, the availability of sufficient freshwater to meet agricultural, urban, fishing, recreational, and other needs depends on properly managing a complex

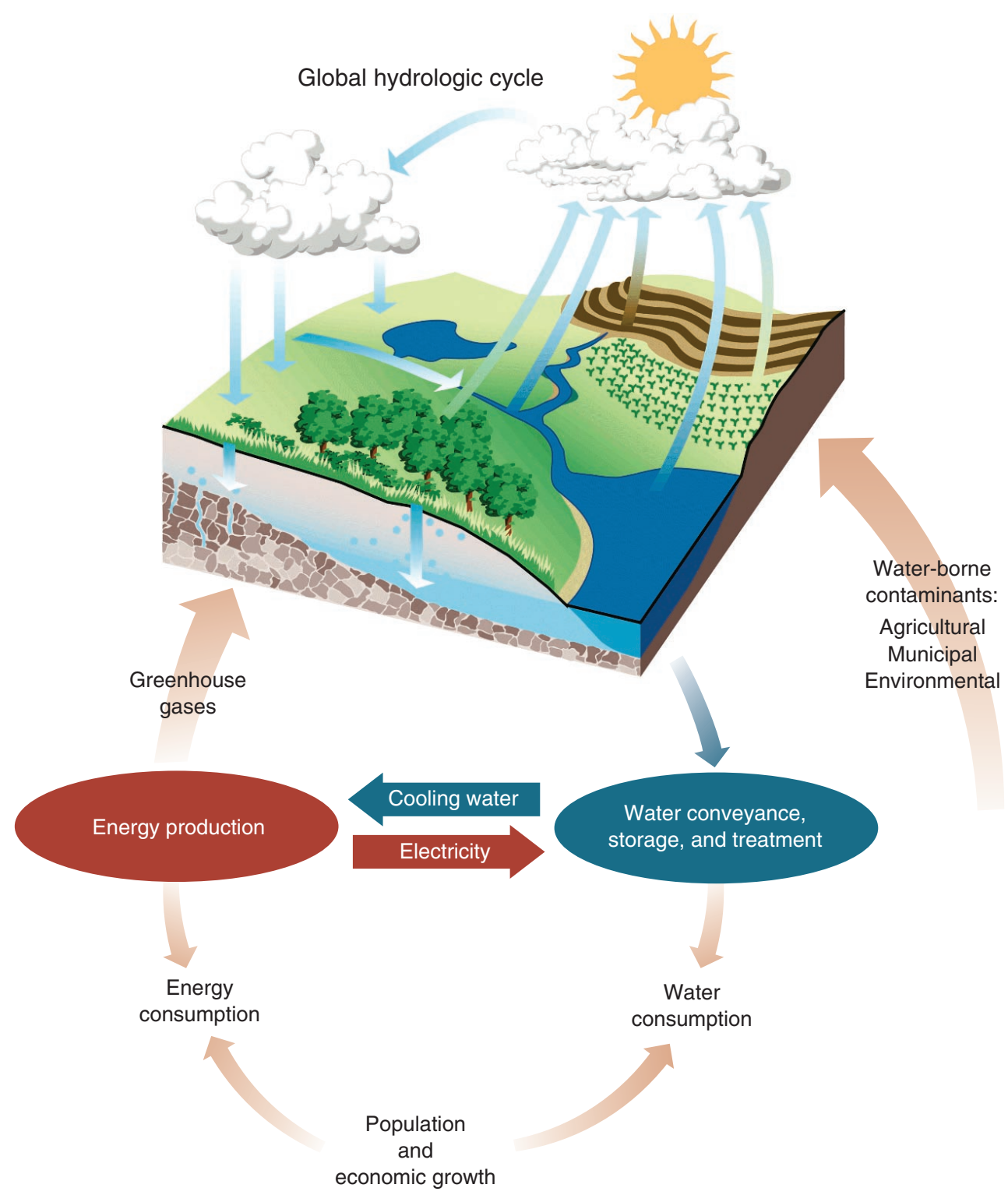

Water and energy are inextricably linked. Energy production is the second largest consumer of the nation's freshwater, after agriculture. The treatment, storage, and distribution of water are dependent on readily available energy. The needs for both resources are expected to grow substantially for the next 25 years.

system of water storage and delivery. In making decisions, water managers are guided by past observations of the natural hydrologic cycle, including such factors as rainfall, the water content of snow, and river flow rates.

These observations are useful only if the future behavior of California's hydrologic system is similar to its past behavior. Yet, such an assumption may no longer be correct. If the natural hydrologic cycle continues to change significantly, water management practices must adapt to the new patterns. These changes require building new reservoirs, pipelines, aqueducts, floodcontrol projects, and treatment plants and in many cases, operating existing facilities differently.

"There's a compelling need for improved water management based on the best models," says Livermore physicist Philip Duffy, who leads the initiative's modeling project and is director of the University of California's (UC's) Institute for Research on Climate Change and Its Societal Impacts. The goal of the modeling effort is to project future changes in the hydrologic cycle in California and determine how those changes will affect the availability of freshwater. Water managers and policy makers would benefit if such projections were available for assessing proposed changes in water management practices.

"We're looking at how water supplies are likely to change during the next several decades," says Duffy. The team's simulations of future water supplies are done on Livermore's massively parallel supercomputers. Fortunately, California's water system is well suited for modeling because most of its supply comes from precipitation or groundwater within the state. Only 5 percent is drawn from out of state (from the Colorado River).

California's water system is dependent on storage of water in reservoirs and in the snowpack. However, few new reservoirs are being built, and increasing 
amounts of precipitation are falling as rain, not as snow.

"The only source that feeds reservoirs and rivers in the summer is melting snowpack," says Duffy. Measurements show that snowpack water levels are dropping as California's climate continues to warm. If that decrease continues, it could reduce late spring and summer stream flows into reservoirs. And unless the state increases its reservoir capacity, additional water supplies cannot be stored during the winter even if river flow rates increase because of the changing precipitation pattern. Ironically, to protect against flooding, water managers may need to lower water levels in reservoirs, effectively reducing the total volume of water in storage. As a result, less water would be available in summer to support agriculture, hydropower production, fisheries, and recreation, thus compounding the state's need for increased storage capacity.

\section{Linking More Detailed Models}

To better understand how these changes will affect California's water supply, Duffy's team is using a sequence of models, starting with global climate models and ending with surface hydrology models. Each successive model increases the simulation's spatial resolution, which improves how closely the results agree with observations. "High spatial resolution is even more important for simulating the hydrologic cycle than it is for simulating climate," says Duffy.

A model with fine resolution can more realistically represent the topographic features of an area and, thus, its surface temperature, which determines whether precipitation is rain or snow. The spatial pattern of precipitation within California is strongly influenced by topographic variations such as coastal hills, inland valleys, and the Sierra Nevada, so surface hydrology models must map topography at a fine resolution to show accurate routes for surface runoff into rivers.
Duffy's team generates the initial predictions of the sequence using a global climate model run at a spatial resolution of about 75 kilometers. Although this resolution is much finer than typical for global models, it does not provide enough detail for the project. Data from the global climate models are then used to drive two regional climate models, one with a grid size of 9 kilometers and the other with a grid of 36 kilometers. Having results from two models helps the team estimate uncertainties in the model predictions.

Next, the researchers feed surface temperatures and precipitation data from the regional climate model into a surface hydrology model run with a lumped-mode grid - that is, each watershed is treated as one irregularly shaped grid cell. This simulation is designed to predict snow depth, soil moisture, surface runoff, and

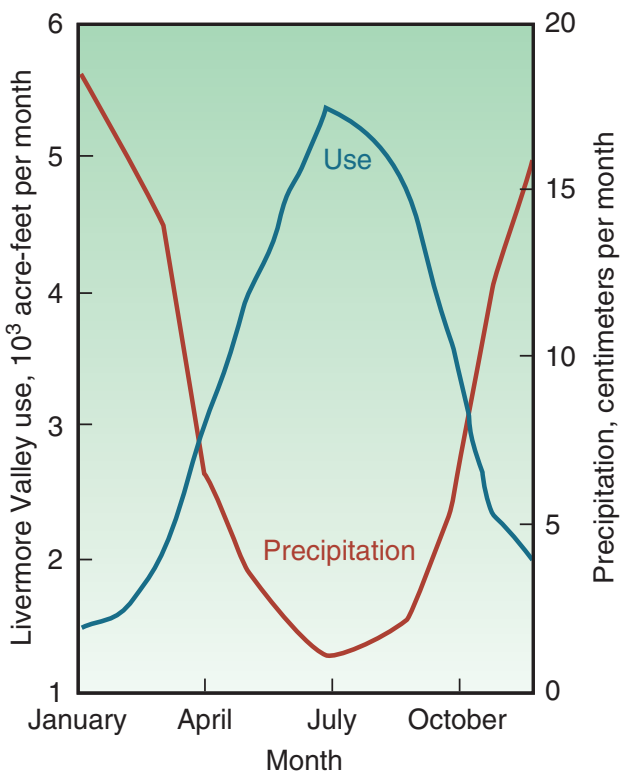

Melting snowpack is the only water source for California reservoirs and rivers in summer, when water usage increases. For example, as the chart shows, residents of California's Livermore Valley (blue line) use the most water during summerthe time of lowest precipitation in the Sierra (red line), where much of the valley's water originates. (1 acre-foot equals 1,214 cubic meters of water.) most importantly, selected stream and river flow rates. The spatial resolution is fine enough to provide the detailed information needed by water managers who oversee different watersheds.

The data generated by the hydrologic model will also be useful for flood control. Because California's water system is used for both flood control and water storage, water managers need accurate predictions of the maximum values for precipitation, runoff, and river flows as well as the averages over time. That way, they can make informed decisions about how much reservoir capacity is needed to absorb surges in river flow and runoff.

A key component of this project is making the research results useful to water managers and policy makers. "Our approach is to predict exactly the same quantities at the same observation points that water managers use to guide their decisions," says Duffy. "For example, when we simulate future climate patterns, we'll predict river flows at locations above major reservoirs. With data from these important reference points, water managers can use the predictions to understand how to operate the water system in an altered climate regime."

\section{Estimating Uncertainty}

Another emphasis of the project is to estimate the uncertainty in the predictions. "We're emphasizing the uncertainties both from a research perspective and in response to discussions with water managers," says Duffy. "They gave us a clear message: 'Tell us the uncertainties associated with your models.' One approach is to compare results from a range of accepted models."

The project team has compared the simulations of present and future climates in California provided by 15 global climate models. These models predict surface temperature, precipitation rate, solid moisture content, water-equivalent snow depth, and other meteorological quantities. Because each model was developed at 


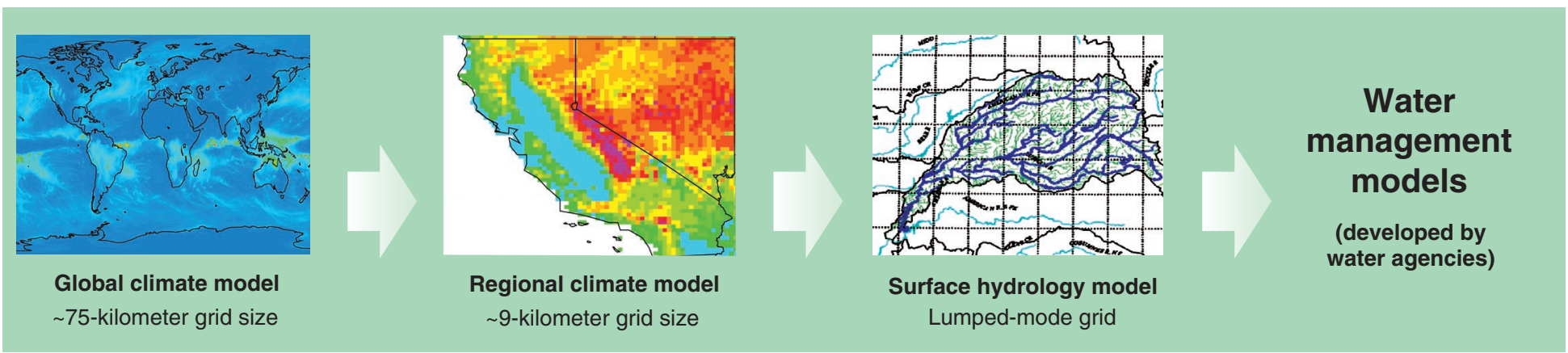

Livermore simulations are being used to project future changes in California's hydrologic cycle and determine how these changes will affect the availability of freshwater. Researchers use a sequence of models, and each successive model increases the simulation's spatial resolution. The surface hydrology models are run with a lumped-mode grid — that is, each watershed is treated as one irregularly shaped grid cell.

a different research institution, each one treats climate physics slightly differently. Thus, the models give a range of predictions for both the present and future climates of the western U.S., which provides a measure of uncertainty.

Initial results from this project have led to endorsements by federal, state, and local agencies for a center to address long-term water-supply predictions for California. Such a center would provide projections of regional climate hydrology to water managers, much as the Program for Climate Model Diagnosis and Intercomparison, established at Livermore in 1989, develops methods to validate and compare global climate models. The proposed center would include participants from the major research groups working to improve the science of predicting future water-supply patterns and problems.

\section{The Threat of Nitrate Contamination}

One of the most important tasks for California water managers is to protect the purity of groundwater, which supplies about half of the state's drinking water. However, since 1988, about one-third of the state wells that supply public drinking water have been abandoned, destroyed, or inactivated, frequently because they have been contaminated with nitrate from fertilized farmland, dairies, feedlots, and septic tanks.
Nitrate, a nitrogen-oxygen compound, is a significant source of nitrogen, an essential nutrient. However, high levels of nitrate in drinking water can cause serious illness and sometimes death. Nitrate poses a special risk for infants. It can diminish the oxygen-carrying

(a)

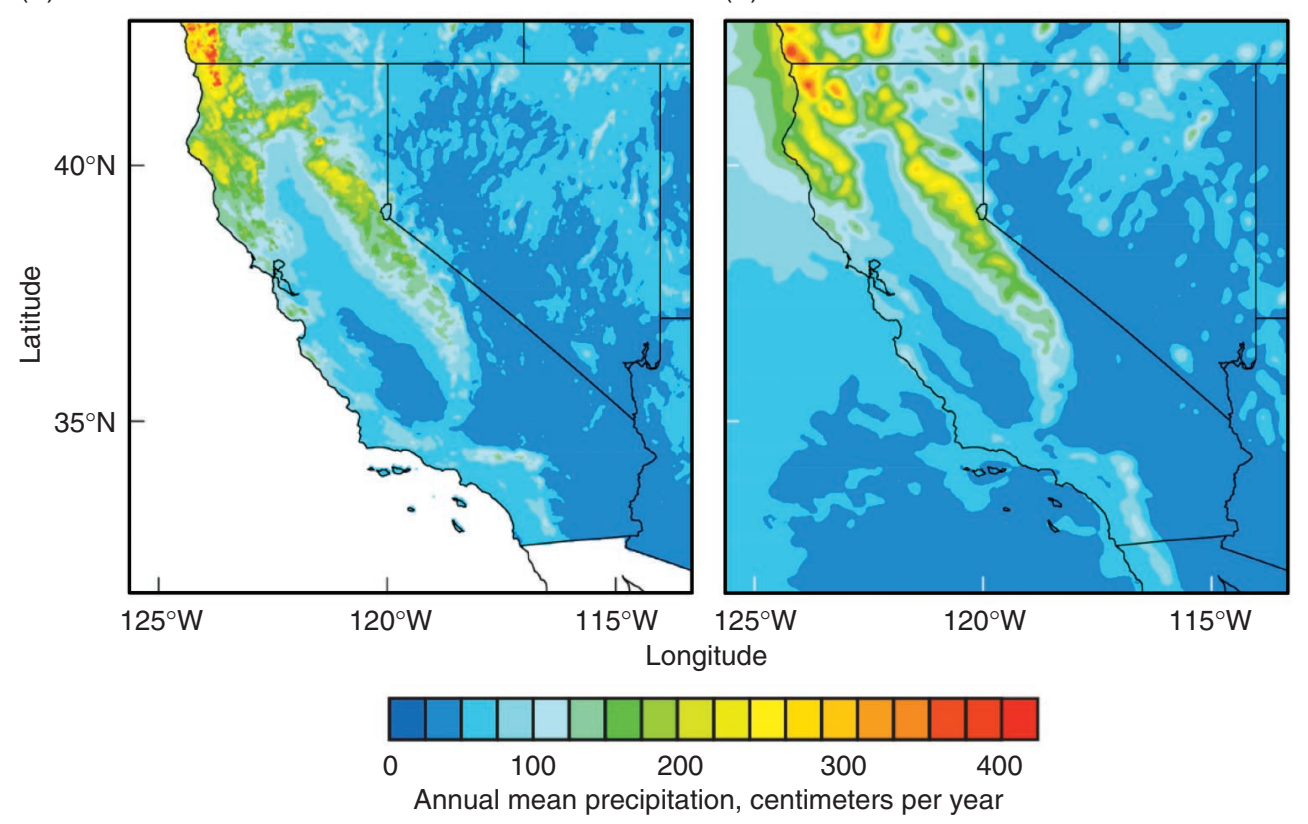

To validate the accuracy of a computer model, scientists compare the model's results with observations. In this example comparison, the Livermore team used (a) the observed mean annual precipitation in the western U.S. from 1971 to 2000 and (b) results from a regional climate model of annual precipitation for that same period. The model's resolution is 9 kilometers. capacity of an infant's blood (called blue baby syndrome), which can lead to death. High nitrate levels can also harm the ecosystems of lakes, streams, and the coastal ocean.

Ten percent of active California public supply wells have nitrate contamination

(b) of (n) 
exceeding the drinking water standard of 45 parts per million, and another 20 percent contain nitrate levels that are significantly above background levels. In agricultural counties, up to 80 percent of groundwater tapped for drinking water is affected or polluted by nitrate. Alternatives such as drilling a new well or treating contaminated water to remove nitrate are costly.

With a better understanding of how nitrate levels in these wells will evolve over time, water managers can decide which approach to use. In addition, their efforts to protect drinking water will be improved if they have more accurate information on how land-use and farming practices affect nitrate levels in groundwater.

The second project of the Water Initiative, which is led by Livermore chemist Brad Esser, is designed to address the nitrate contamination problem. Esser's team is studying the natural processes that control groundwater nitrate movement and degradation. In this effort, the researchers are applying new diagnostic tools and computer models and drawing on Livermore expertise in isotope hydrology, groundwater modeling, and molecular biology. They are studying the problem at the laboratory, farm, and water-basin scales.

\section{Solubility, Stability Are a Problem}

Because of its mobility, nitrate readily contaminates groundwater. Nitrate is mobile because it is soluble and stable in oxygen-rich water and does not bind readily to soils. In oxygen-deficient waters, certain bacteria convert nitrate to molecular nitrogen - a harmless component of the atmosphere - in a process called denitrification. Esser and his colleagues are studying microbial denitrification under laboratory and field conditions, so they can determine a groundwater basin's capacity to assimilate nitrate and understand how nitrate distributions will evolve over time.
"We are developing better tools to detect and understand denitrification," says Esser. For example, one test is designed to determine whether bacteria capable of denitrification are present and if they are removing groundwater nitrates. The test detects a gene in the bacteria that indicates the presence of enzymes responsible for the process. In addition, Livermore scientists have developed a mass-spectrometry method to quantify the amount of nitrogen that has dissolved in groundwater as a result of denitrification. The two tests allow researchers to study what factors control the rate of denitrification in groundwater.

Water managers also need to know the source or sources of nitrate contamination. For example, if the source is septic discharge, then converting septic tanks to sewer lines will be more effective than implementing a farm fertilizer management program. Esser notes that many water contaminants, such as trichloroethylene, are found in high-concentration plumes with easily identified sources. Groundwater nitrate contamination, however, is often low-level and pervasive, reflecting multiple sources such as septic systems or synthetic fertilizer or manure used on crops, so identifying nitrate sources is more difficult.

To understand groundwater flow paths and trace contaminants such as nitrate back to their source, the Livermore team is combining an isotopic technique to determine groundwater age (see S\&TR, November 1997, pp. 12-17) with groundwater flow models that take advantage of the Laboratory's supercomputing capability (see $S \& T R$, June 2001, pp. 13-21).

For this project, the team is working with colleagues from the UC Cooperative Extension and UC Davis in a study of a dairy farm in California's Central Valley. The scientists are installing multilevel monitoring wells to determine groundwater flow paths and to understand nitrate transport and denitrification.
The team is also working with the Santa Clara Valley Water District to characterize nitrate transport in the Llagas basin, a primary source of the groundwater needed to meet future demands in southern Santa Clara County. The basin has pervasive nitrate contamination in shallow aquifers but little contamination in deep aquifers.

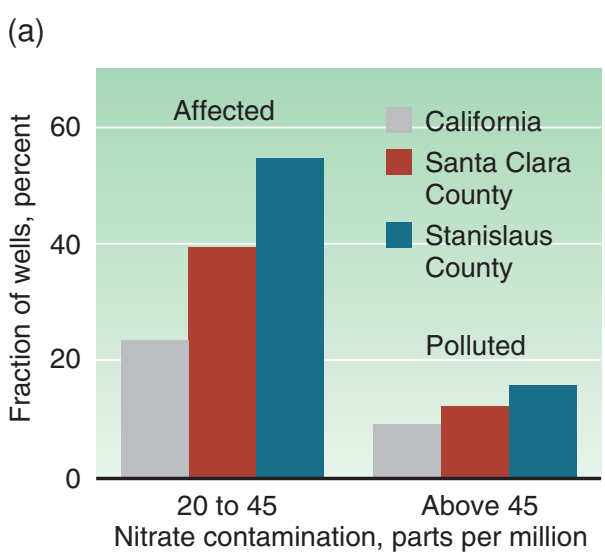

(b)

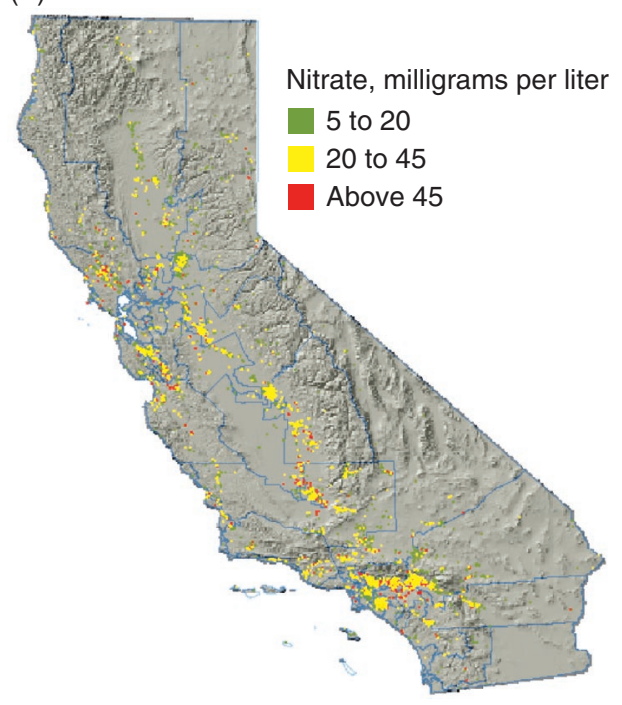

(a) About 10 percent of active California public water-supply wells have nitrate contamination exceeding the drinking water standard of 45 parts per million. In agricultural areas, such as Stanislaus County, up to 80 percent of groundwater is affected or polluted by nitrate. (b) The map shows the extent of nitrate contamination throughout the state. 
"Deep wells in the basin do not contain nitrate either because denitrification is occurring or because the deep water is old and uncontaminated," says Esser. "We'd like to determine which process is at work here. We also want to identify the source of nitrate in the basin's shallow wells."

For this project, the Livermore scientists are using geochemical models to identify input of nitrate from synthetic fertilizer and developing analytical methods to distinguish septic discharge from manure as sources of groundwater nitrate. So far, they are finding that shallow wells contain young water, whereas the deeper water is older and oxygen deficient. However, they have found no evidence of denitrification under current conditions, indicating that nitrate contamination has not yet penetrated deeper parts of the basin.
The researchers are incorporating these data into a highly resolved threedimensional (3D) model of Llagas basin groundwater flow and transport. The flow field is based on a 3D geostatistical model of sediment distribution that is derived from drilling logs of more than 300 wells. Results from these simulations will be used to develop groundwater resources in the basin and protect the basin from future nitrate contamination.

\section{Creating “New" Water}

Many wells closed by nitrate contamination could be reopened if a cost-effective treatment were found. One significant cost of the water treatment technologies developed in the 1960s and 1970 s is their high energy use. For example, one-half the overall cost of seawater desalination using reverse

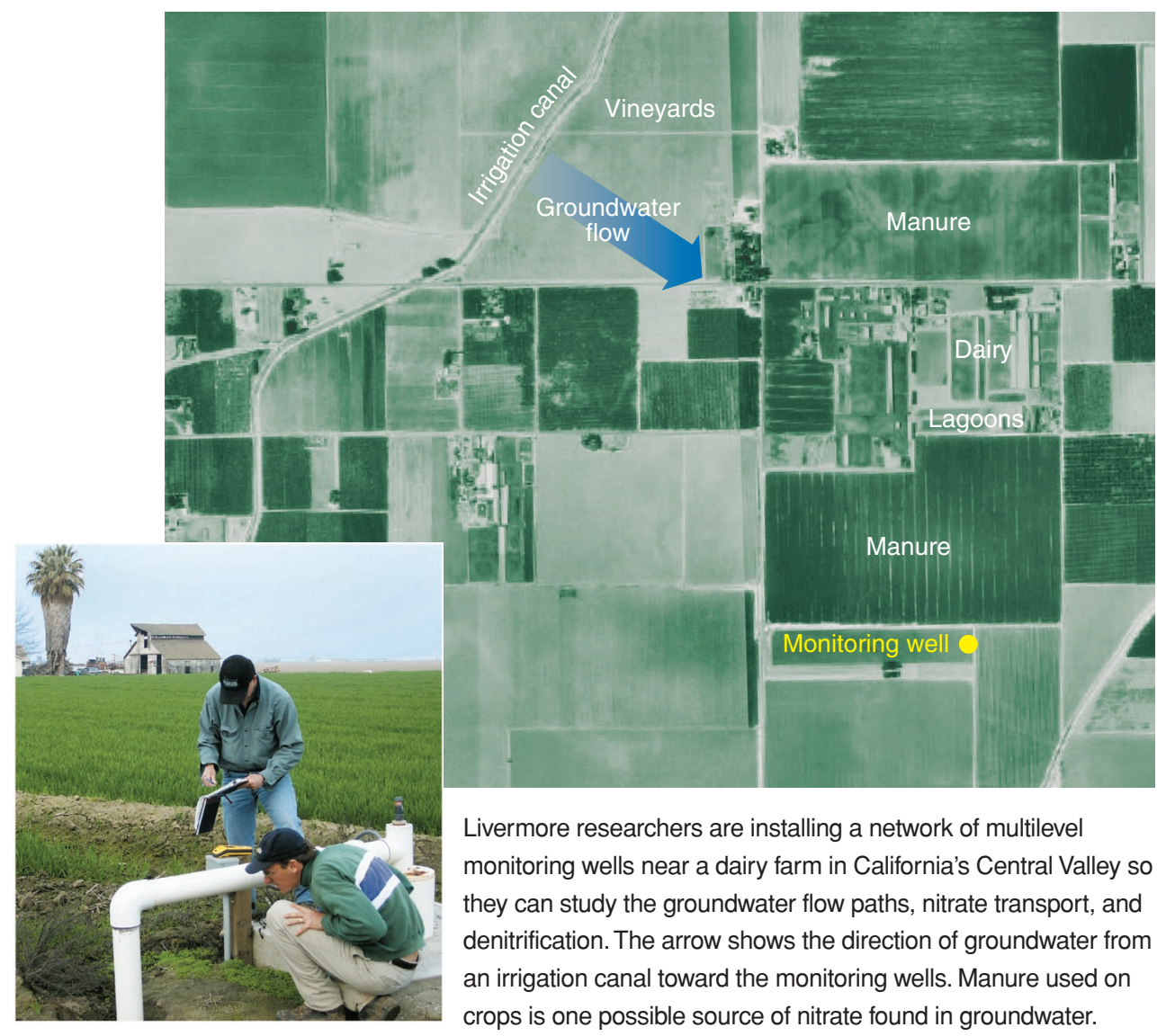

osmosis is the cost of energy. Another treatment technology, electrodialysis, is more energy efficient at removing salt from less saline, or brackish, waters. However, even electrodialysis is not a cost-effective treatment method for the growing volumes of marginally impaired waters - those that contain small concentrations of one or more contaminants but are otherwise adequate for domestic use. A better approach would be selective technologies designed to extract only a few problem species, which would reduce both the volume of the waste stream and the overall energy cost for treatment.

The third project of the Water Initiative is focused on providing a cost-effective option for treating these marginally impaired waters. If successful, the new technology would undoubtedly help increase water supplies everywhere. In this project, lead investigators geochemist Bill Bourcier and engineer Kevin O'Brien are creating energy-efficient membranes to replace the solid polymer membranes used in electrodialysis. This approach taps Livermore's capabilities in computational chemistry and nanomaterials synthesis. Says Bourcier, "We want to use it to treat brackish water in a way that sharply lowers operating costs."

In electrodialysis, transport of either positively charged ions (cations) or negatively charged ions (anions) through copolymer membranes is driven by a voltage applied by a pair of flat electrodes. The ions are driven toward the electrode with the opposite charge. Water flows between alternate cation-permeable and anion-permeable copolymer membrane sheets sandwiched between the electrodes and separated by spacers. As water flows between the membranes, salt is removed from one compartment and concentrated in adjacent compartments, with up to a hundred or more membrane pairs per stack. A manifold separates the exiting fluid into a relatively salt-free permeate product and a salt-enriched brine for disposal. 
The current electrodialysis technology is inefficient because it forces all dissolved ions, including those that are considered benign or healthy, through the solid membranes. The Livermore team is replacing these membranes with "smart" membranes of polycarbonate - the material used to make compact disks - which are then coated with a thin layer of gold. (See the top left figure on p. 12.) These smart membranes can be designed to selectively remove only one contaminant of interest by specifying the pore size, voltage, and electric field to attract the target contaminant. For nitrate cleanup, a small fraction of a volt will be applied to each membrane, and the overall electric field will measure 1 to 2 volts per membrane pair.

"With current electrodialysis design, every ion is pushed through a solid plastic membrane that has high electrical resistivity and no selectivity," Bourcier says. "The smart membrane is designed to have low resistivity to ion transport and, therefore, high energy efficiency - up to 50 percent greater than standard electrodialysis."

\section{Pores Drilled in Smart Membranes}

The membranes have pores drilled to an optimal size for selective removal of the ions of interest. If the system is optimized for nitrate ions, for example, those ions will preferentially pass through the pores, while others remain with the stream of water. The nitrates can then be collected in the waste stream.

The pores are created with an etching process using Livermore's ion-beam technology. For nitrate treatment, the membrane pores are about 10 nanometers in diameter. (See the bottom left figure on p. 12.) Current polycarbonate membrane samples contain about 1 billion holes per square centimeter.

Membranes are being designed using quantum mechanical modeling, which simulates the ions of interest in electrolyte solutions in varying concentrations.

The modeling work, which is done on
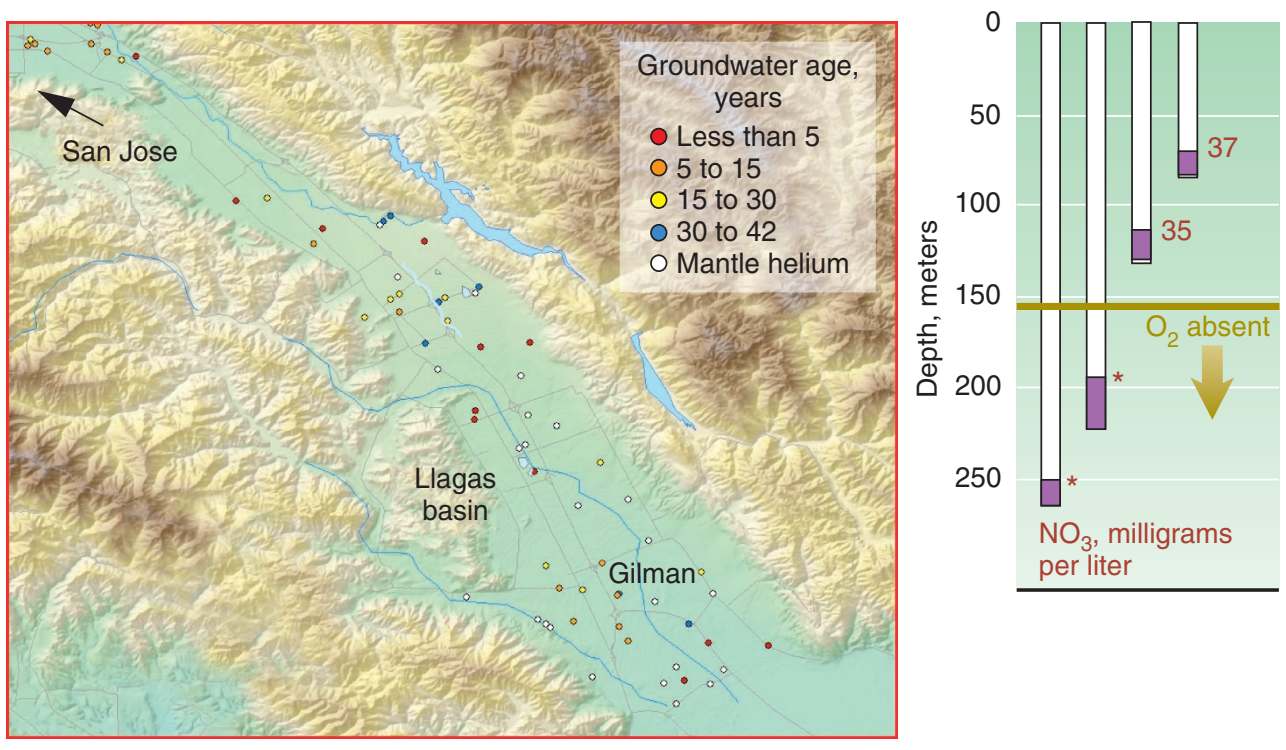

Livermore is characterizing the Llagas groundwater basin, which is managed by the Santa Clara Valley Water District. As shown in data from wells at one location (Gilman), the basin has pervasive nitrate $\left(\mathrm{NO}_{3}\right)$ contamination in shallow aquifers but little contamination in deep aquifers, where oxygen $\left(\mathrm{O}_{2}\right)$ is absent. $\left({ }^{*}=\right.$ less than 1 milligram per liter.)

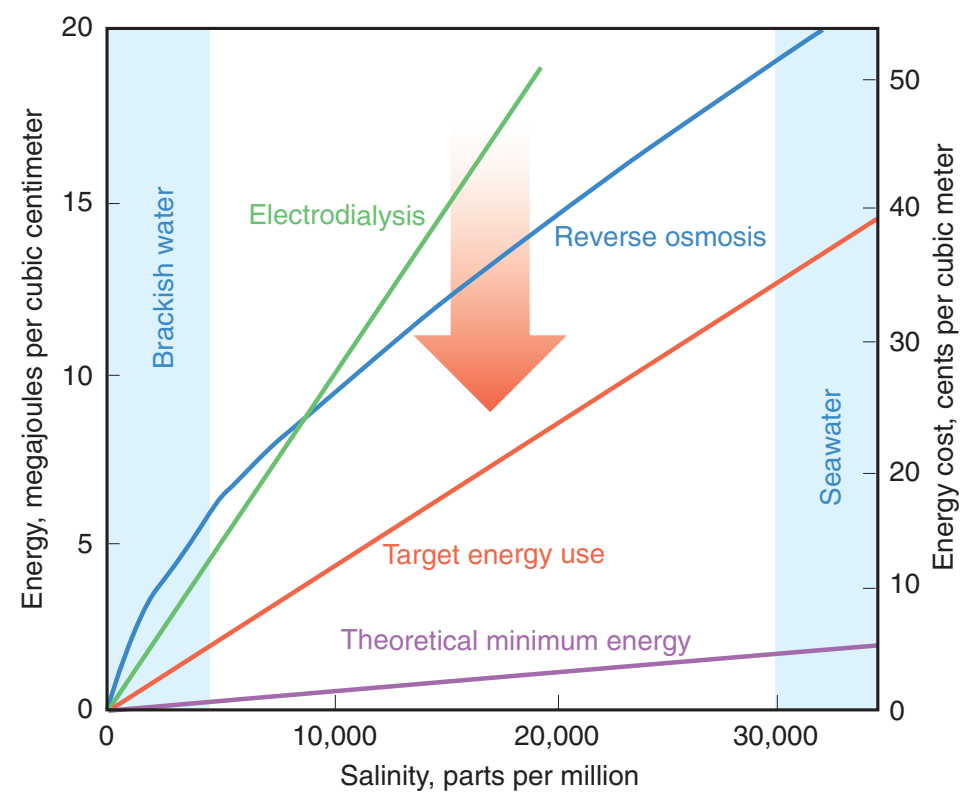

Livermore researchers are evaluating a modified electrodialysis setup to lower the energy costs for this process by 50 percent. If the goal is met, electrodialysis would become a much more important technology in treating brackish water. 


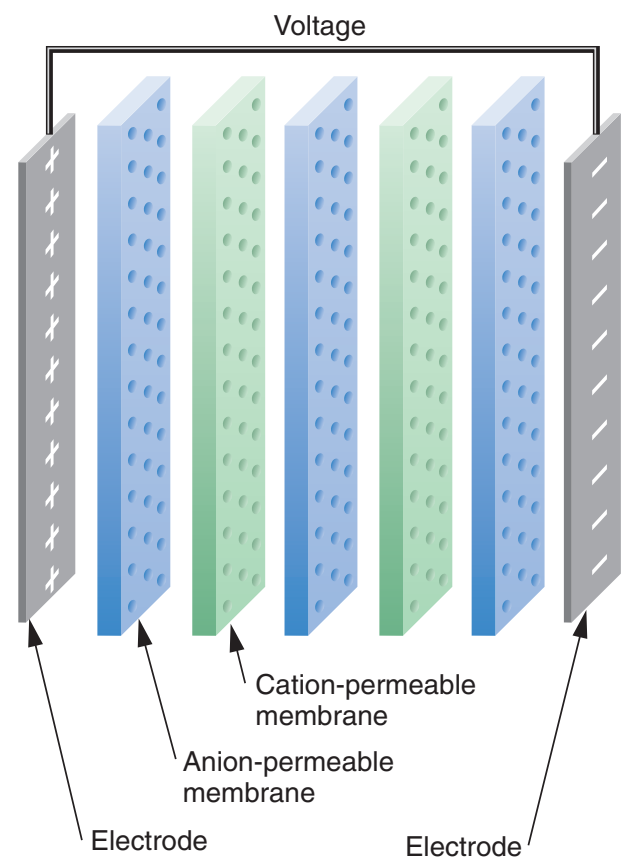

Livermore's modified electrodialysis technology replaces the solid polystyrene membranes with "smart" membranes of gold-coated polycarbonate. By specifying the pore size, voltage, and electric field that will best attract and isolate a target contaminant, researchers can design each membrane to selectively remove only one contaminant of interest.

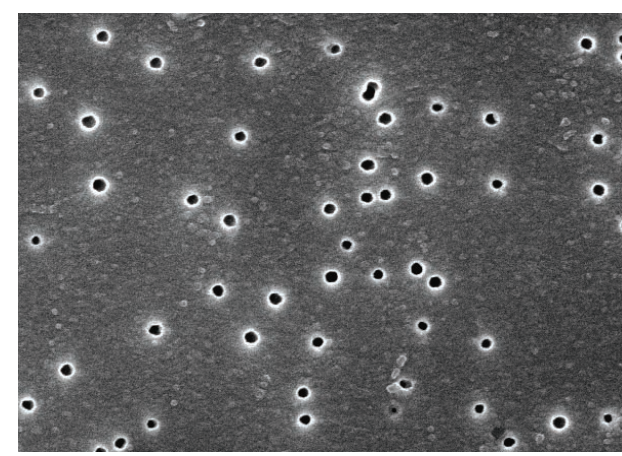

This image shows a smart membrane with pores drilled to 10 nanometers in diameter-the size needed for nitrate ions to pass through. supercomputers and led by physicist Bill Wilson, uses a numerical method for calculating the electrostatic field in the vicinity of the charged membrane pore surfaces. The modeling takes into account an ion's unique 3D geometry and electronic charge distribution. Its motion through the membrane is determined by potentials applied to the membrane elements. The modeling results determine the pore size and the optimum voltage to be applied to the membrane. "Water purification research has always been an empirical field," says Bourcier. "We're modeling the membranes before they are manufactured to avoid a lot of trial and error."

The project team also wants to research contaminants besides nitrate. Many community wells do not meet the new lower limits for arsenic, but treating them with reverse osmosis would cost millions of dollars. Electrodialysis with smart membranes could be a viable alternative. Other contaminants of interest include perchlorate, a by-product of rocket fuel that is found in Santa Clara County groundwater, and selenium, a natural element found in Central Valley groundwater and elsewhere.

Within a year, the researchers plan to test a prototype unit in the field, and they are evaluating potential demonstration sites. Bourcier believes that the technology will be capable of purifying a metric ton of water for 20 cents in energy costs, half of current costs. In addition, large-scale smart membrane manufacturing would cost less than a dollar per square meter.

The team is confident the pores also could be used to trap minor contaminants, such as perchlorate molecules, which typically are present in parts-per-billion concentrations. For those applications, the voltage applied to the membranes would be turned up to electrochemically destroy the perchlorate molecules and, thus, eliminate any waste stream.

In a similar manner, a membrane could be designed to selectively remove viruses and then deactivate them. Bourcier foresees specialized membranes for the military, such as a unit mounted on a Humvee to purify brackish water for troops in the field, or membranes designed to remove chemical and biological warfare agents from water. The technology could also be used to purify the wastewater from the production of oil, gas, and coal and to recover metals in industrial wastewater and in silicon chip manufacturing. "There are

(a)
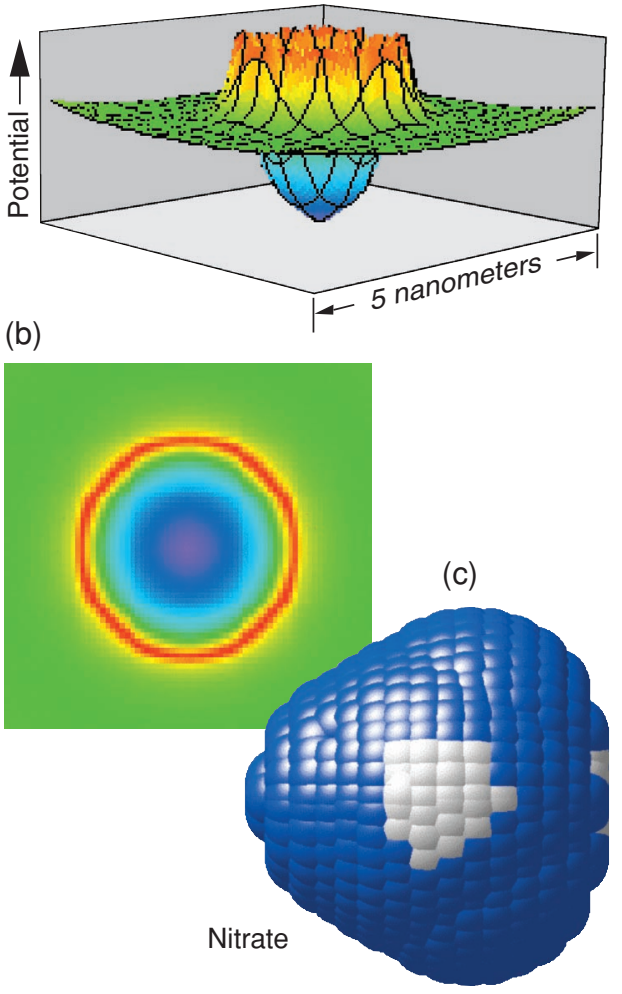

Quantum mechanical modeling is being used to design the smart membranes. (a) A simulation of a smart membrane pore shows the strong electric field gradients near the pore surface, where blue is the lowest voltage and red is the highest. The electrostatic forces will induce a nitrate molecule to pass through the pore where the molecule can be collected in a waste stream. (b) The same gradient is shown from the top, looking down on the pore. (c) This model shows the charge distribution of a nitrate ion, where the white area denotes an area of negative charge. 
many tricks we can try," says Bourcier. "If we're successful, we'll see much greater use of electrodialysis."

\section{California Again Leads the Nation}

Newmark says she is seeing results from early progress of the Water Initiative. For example, Livermore researchers have received letters of endorsement from many water districts and agencies. "Successful development of these tools and methods may revolutionize the options water managers have to address the challenges facing them."

Although the immediate focus is California, the Livermore tools and methods can be applied anywhere in the nation. The state, Newmark says, is akin to "a canary in a coal mine" because looking at California's water picture is like looking at America's water future.

-Arnie Heller
Key Words: denitrification, electrodialysis, global climate change, hydrologic cycle, Laboratory Directed Research and Development, nitrate contamination, water purification.

\section{For further information contact Robin Newmark (925) 423-3644 (newmark1@IInl.gov).}




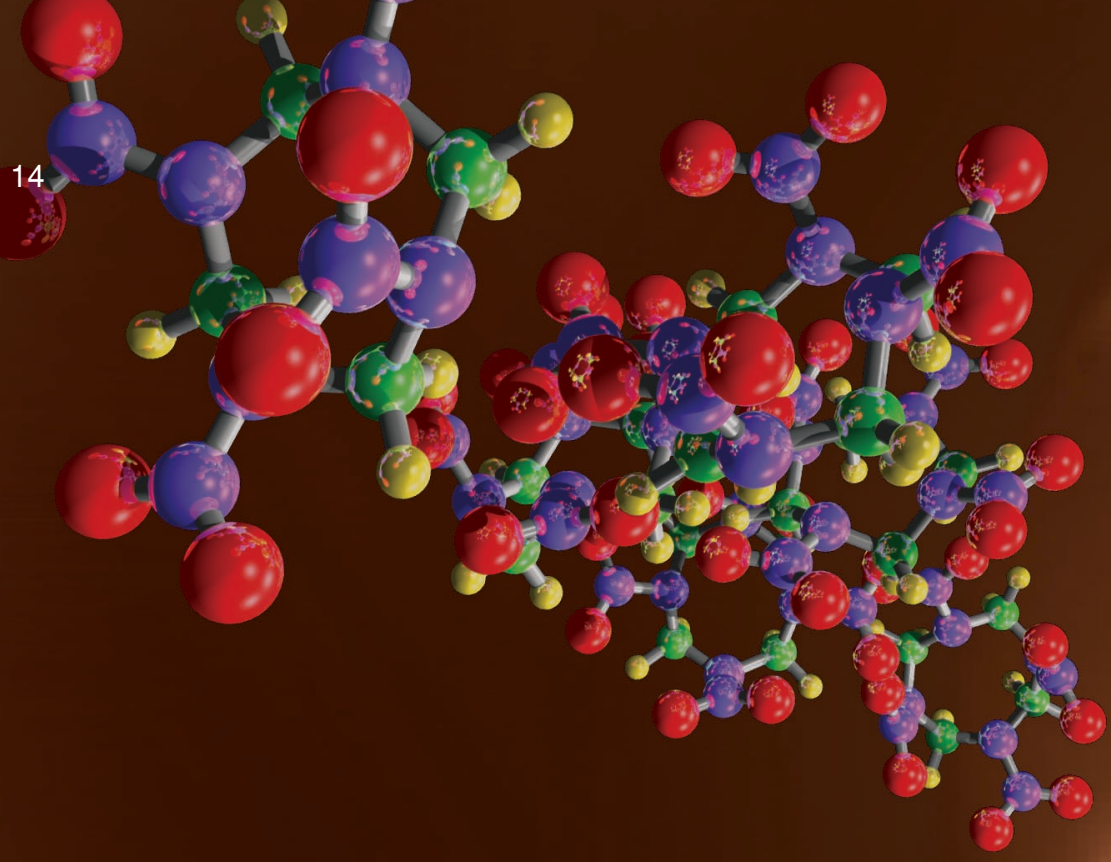

S\&TR July/August 2004

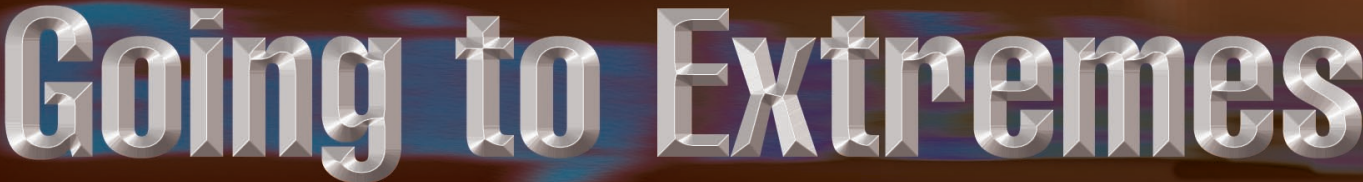

\section{Researchers}

turn up the heat

and pressure

to understand

chemical reactions

under extreme

conditions.
ITTLE is known about the chemistry that produces minerals in the deep regions of Earth or that creates the ammonia oceans of the outer planets and moons. What is known is that an element's fundamental properties - its optical, structural, electrical, and magnetic characteristics - can completely change when it is put under extreme conditions. In fact, when a material is exposed to pressures up to one million times the atmospheric pressure at Earth's surface and to temperatures above $6,000^{\circ} \mathrm{C}$, its atoms can completely rearrange themselves, rendering an entirely new substance.

Similar conditions exist near Earth's core and in other planets, both inside and outside the solar system. They also occur in high-explosive reactions and impacts from meteorites and comets. Understanding chemical reactions at such extreme conditions is a critical research area for the National Nuclear Security Administration's (NNSA's) Stockpile Stewardship Program. To maintain the reliability and performance of the nation's nuclear weapon stockpile, scientists must be able to more accurately predict the performance of high explosives (HE). However, to refine the computer codes that simulate these reactions, they need more detailed information on the chemical, mechanical, and energetic properties of the water, carbon, and nitrogen produced by an HE detonation.

At Lawrence Livermore, much of this research is conducted by the Extreme Chemistry Group in the Chemistry and Materials Science (CMS) Directorate. According to chemist Larry Fried, who leads this group, the team's objective is to understand the physical and chemical processes at extreme conditions as well as scientists now comprehend those processes at ambient conditions. 


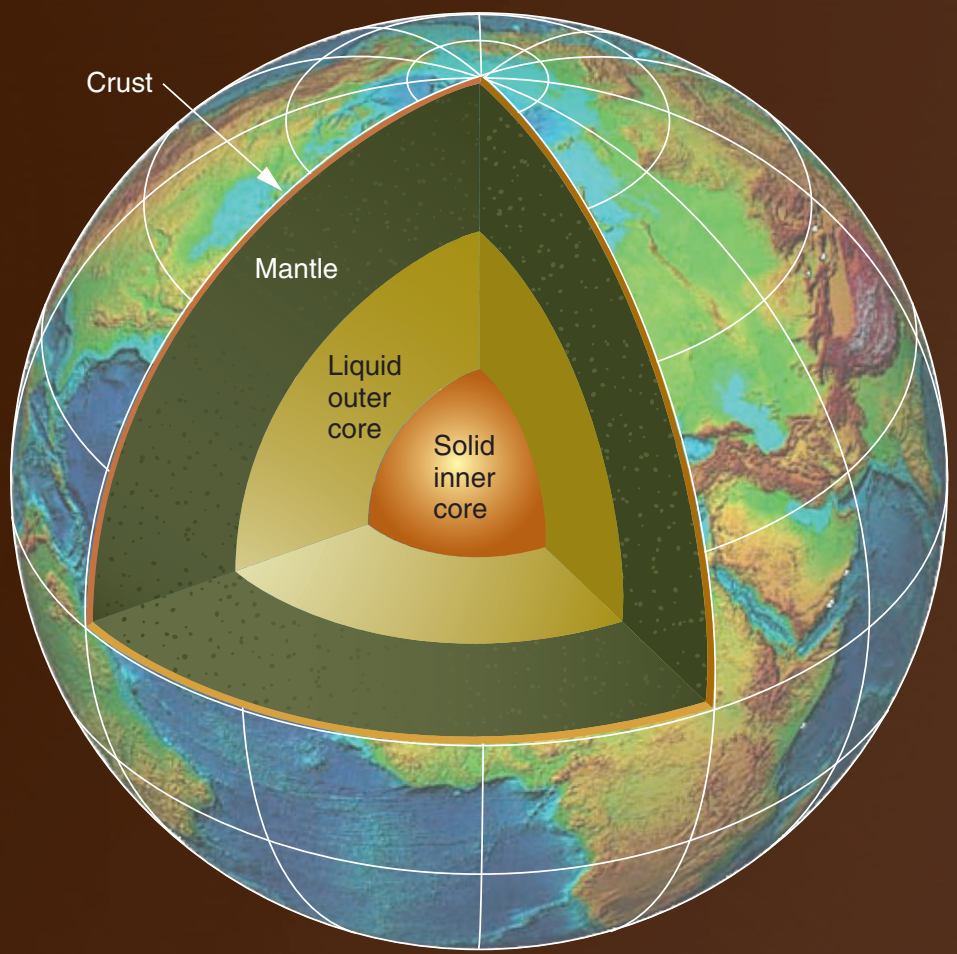

Livermore's Extreme Chemistry Group studies chemical reactions that occur under high-pressure, high-temperature conditions-up to one million times the atmospheric pressure at Earth's surface and temperatures above $6,000^{\circ} \mathrm{C}$. Similar conditions exist near Earth's core and in other planets.

The group's research applies not only to stockpile stewardship but also to emerging technologies in nanoscale and energetic materials. "We're finding answers to important technical questions regarding reaction chemistry," says Fried. "What we're learning can be applied to various phenomena, from planetary evolution to new states of matter." (See the box on p. 16.)

\section{Achieving the Extreme}

An essential element in studies of extreme chemistry is a material's equation of state - a mathematical expression showing the relationship of a material's pressure, temperature, and density. Many of the Laboratory's high-temperature, high-pressure experiments are designed to obtain more accurate data on the equationof-state properties for various materials.

Measuring these properties takes ingenuity and a host of technologies. For example, two-stage gas guns at Livermore and at the Nevada Test Site have been instrumental in providing equation-ofstate data. (See $S \& T R$,

pp. 13-19; June 2004, pp. 4-11.) With gas guns, scientists can fire hypervelocity projectiles into highly instrumented targets, shocking matter to extreme conditions for a millionth of a second or less.

These experiments create pressures of a million-plus atmospheres, temperatures up to thousands of degrees, and densities several times that of a material's solid state. Shock-compression experiments have been used to evaluate liquefied gases such as hydrogen, nitrogen, carbon dioxide, and oxygen as well as solids such as aluminum, copper, tantalum, and carbon (graphite).

Mixtures of elements are more difficult to characterize. For those experiments, scientists use the diamond anvil cell, a device small enough to fit in the palm of one's hand. (See the figure on p. 16; also see $S \& T R$, March 1996, pp. 17-27.)

Diamond anvil cells can create the temperature-pressure conditions required to transform a substance: up to about 3.6 million atmospheres of pressure at room temperature and 1.7 million

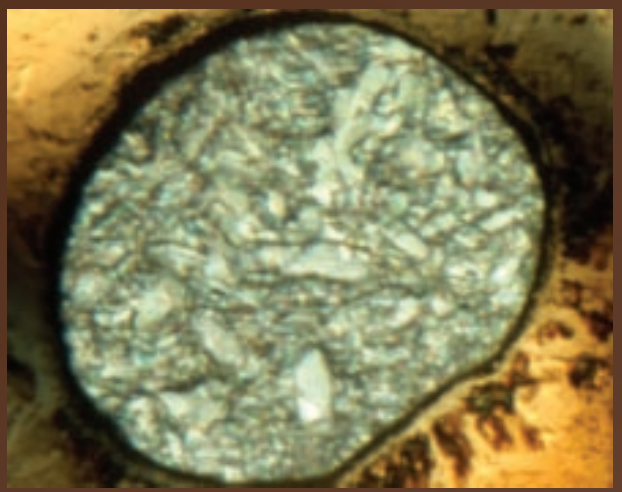

Formic acid reacts to modest pressures and temperatures (about 2,000 atmospheres and $\left.150^{\circ} \mathrm{C}\right)$. 


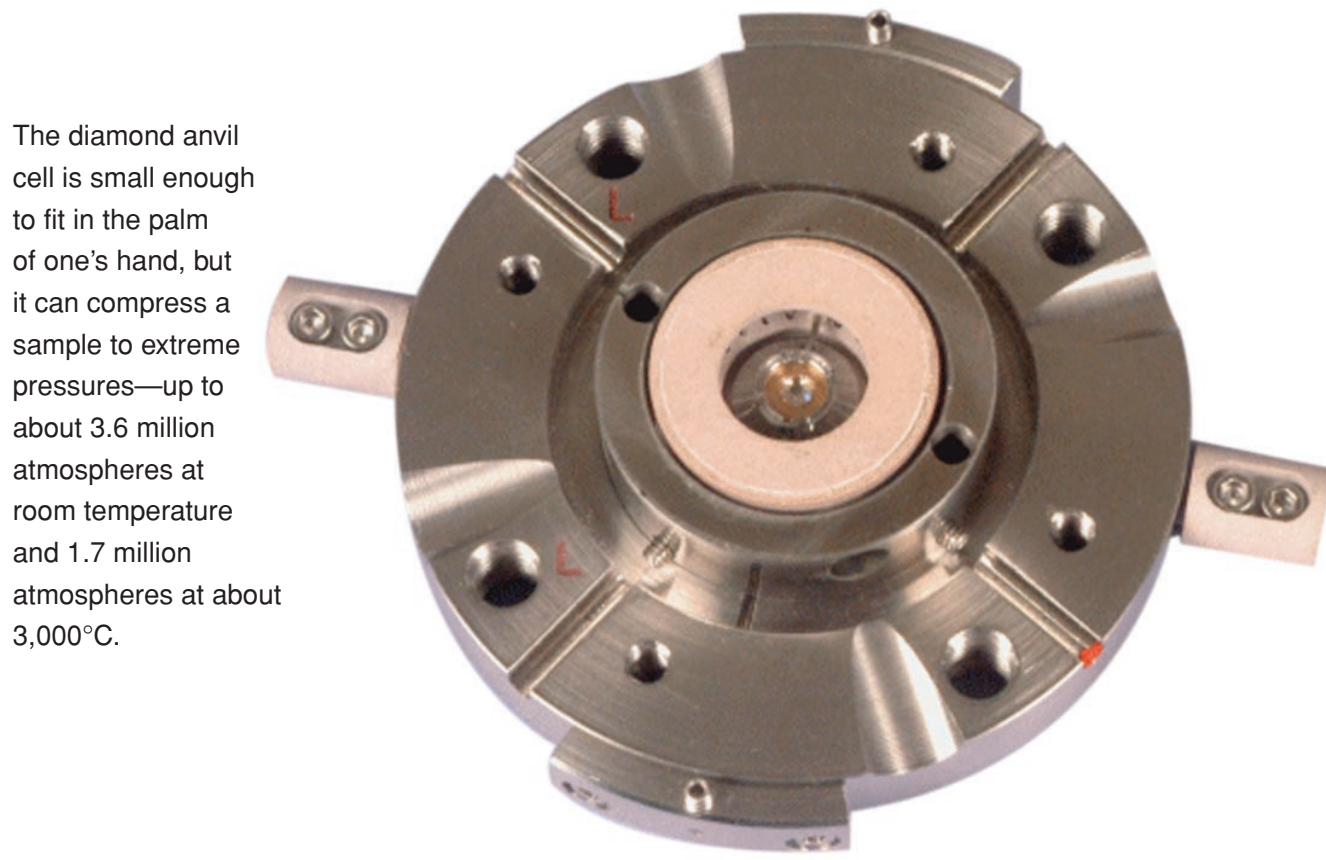

atmospheres at about $3,000^{\circ} \mathrm{C}$. Lasers can also be used to heat the samples in a diamond anvil cell, so that temperatures reach nearly $6,000^{\circ} \mathrm{C}$ at pressures below 1 million atmospheres. By comparison, the Sun's surface is about $5,500^{\circ} \mathrm{C}$.

One advantage of the diamond anvil cell is that is does not necessarily destroy the sample being tested. "In shock experiments, the sample is destroyed, and the reaction occurs in less than a microsecond," says physicist Bill Nellis, who worked on some of the Laboratory's first gas-gun experiments and is now at the Harvard University Lyman Laboratory of Physics. (See S\&TR, September 1996, pp. 12-18.) "With the diamond anvil cell, samples can be held under controlled extreme conditions long enough for us to observe the reaction."

\section{Predicting New Materials}

A few years ago, using computer simulations, theoretical chemist Riad Manaa predicted the possibility of a fullerene made of 60 purely single-bonded nitrogen atoms. (See $S \& T R$, June 2001, pp. 22-23.) Although still strictly theoretical-no naturally occurring polymeric forms of nitrogen have ever been found - the calculations have shown that it may be possible to link together six molecules of $\mathrm{N}_{10}$, or dipentazole, to create $\mathrm{N}_{60}$, a fullerene expected to have unprecedented energetic potential. $\mathrm{N}_{10}$ has yet to be synthesized, but simulations show that linking two stable pentazole $\left(\mathrm{N}_{5}\right)$ ions could create the metastable building block needed to put together a nitrogen fullerene. (See the figure at right.)

Also necessary for the complex work would be extreme chemistry. Tremendous pressures would be needed to force the dipentazole molecules into the novel configuration.

The first fullerene, $\mathrm{C}_{60}$, was synthesized in the laboratory nearly 20 years ago and named after R. Buckminster Fuller, whose geodesic dome is brought to mind by the shape of the fullerene molecule. The discovery of $\mathrm{C}_{60}$ is considered by many to be the beginning of nanotechnology. Says Livermore chemist Larry Fried, "This work on $\mathrm{N}_{60}$ may mark the beginning of the field of extreme nanotechnology."

The prediction of new forms of polymeric nitrogen is not new, however. More than 20 years ago, theoretical physicists Andy McMahan and Christian Mailhiot predicted that if squeezed hard enough, molecular nitrogen could be turned into a solid-a covalently bonded nonmolecular network like diamond. In 2002, Alexander Goncharov, now with Livermore, conducted experiments that confirmed the McMahan and Mailhiot prediction. "The calculations were not exactly in concert with the original prediction," says Fried, "but they did show that a nonmolecular state of nitrogen could be created with extreme chemistry."

Manaa hopes to see this same progression with his group's prediction of $\mathrm{N}_{60}$ and other nitrogen fullerenes. (See $S \& T R$, December 2003, pp. 20-21.) And while scientific discovery rarely happens overnight, the past decade's advances in computing capabilities and the strides made in extreme chemistry are continually pushing theory to something more tangible.

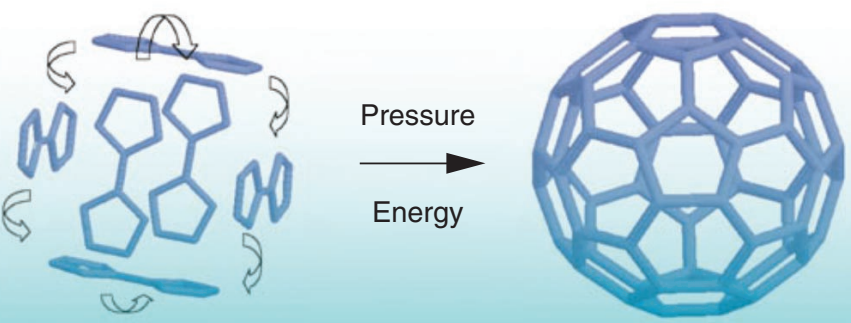

Calculations show that six molecular units of $\mathrm{N}_{10}$ can be combined to form the nitrogen fullerene, $\mathrm{N}_{60}$, which is expected to have unprecedented energetic potential. 
Another option for extreme chemistry research is radiation technology. For example, Livermore researchers are conducting experiments on the new high-pressure x-ray beam line at the Advanced Light Source at Lawrence Berkeley National Laboratory. In the first experiment at the new facility, they observed the pressure-induced reactions of white phosphorous. (See the figure below.) They have also used Lawrence Berkeley's synchrotron infrared beam line to monitor chemical reactions in experiments with the diamond anvil cell.

To improve experimental capabilities for high-pressure materials studies, the Laboratory has joined the High Pressure Collaborative Access Team (HP-CAT). This collaboration is developing new beam lines at the Advanced Photon Source at Argonne National Laboratory for such research as characterizing materials at pressures greater than 500,000 atmospheres and improving x-ray diagnostics for shock-wave experiments.

Chemical kinetic studies are yet another way to look at reactions under extreme conditions. With an infrared system, scientists can monitor spectral features during a reaction, which allows them to study the process of product formation. From these observations, they can then determine the activation energy - the energy required for reactant A to become reaction product B. By better understanding activation energy, scientists can more accurately predict the pressure dependence of chemical reaction rates.

\section{Tailored High Explosives}

The Livermore team uses the data generated from experiments to refine the computer codes that simulate HE performance. Theoretical chemist Riad Manaa says, "We know how to engineer high explosives, but we don't know how they work on an atomic level-how and why they release energy. By improving our predictive capabilities, we can design $\mathrm{HE}$ materials that are safer and more energetic than the ones currently used."

For example, a new trend in HE formulations is to add nanometer-scale metal particles to the mix. Metals make an HE reaction hotter but reduce its pressure. Very small metal particles react much more easily than large metal particles. In the right proportion, metals can almost double the energy content of an explosive, but the challenge is finding the optimal mix. A formulation with too much metal will not burn completely, so the pressure exerted in the explosion may be lower than needed. If metal levels are too low, the reaction may not produce the energy required for a specific application. Heavy metals such as tungsten, titanium, and zirconium can also be used to alter the energy delivery rate of a reaction.

"With computer simulations," says Fried, "we can better understand how to customize materials for a specific target or situation." This capability is of particular interest to the Department of Defense (DoD) because it will allow scientists to develop weapons systems that reduce collateral damage, say, when targets are near an enemy's weapons stockpiles or a civilian structure.

One code the team uses to model detonations is CHEETAH, which was begun in 1993 by Fried and his colleagues. (See S\&TR, November 1997, pp. 21-23.)

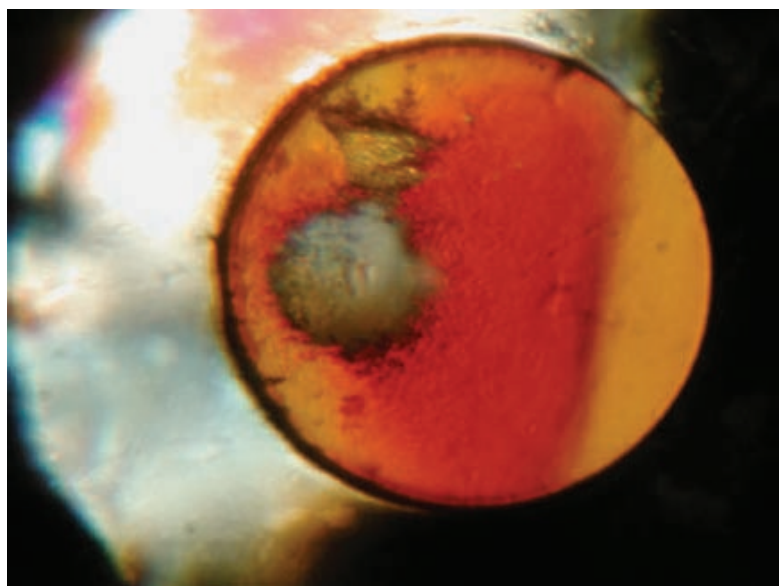

CHEETAH uses data from high-pressure experiments to simulate the performance of different $\mathrm{HE}$ formulations. Used by about 300 Department of Energy and DoD contractors, it allows scientists to determine how best to mix materials for various applications. For example, a shaped charge designed to penetrate armor must deliver its energy quickly, say, in 10 microseconds. By contrast, high explosives used in rock blasting are more effective if energy is delivered over tens of milliseconds. Researchers can use CHEETAH to tailor formulations for specific purposes and to examine several mix options without the time and expense involved in conducting small-scale experiments.

Fried is now linking CHEETAH to Livermore's hydrodynamic codes, so it can model the chemistry of entire systems of materials. "Historically, most chemical studies have examined individual materials in isolation," says Fried. "But with the advances in algorithms and computing power, we've moved from looking at elemental hydrogen to HE mixtures to whole explosives systems. These calculations, which were impossible to do 20 years ago, allow us to study systems such as warheads, reactive armor, or target effects."

Another series of calculations modeled the rapid decomposition of HMX, a commonly used propellant and explosive.
Pressure-induced reactions occur in white phosphorous during the first experiment on the new beam line at the Advanced Light Source at Lawrence Berkeley National Laboratory. 

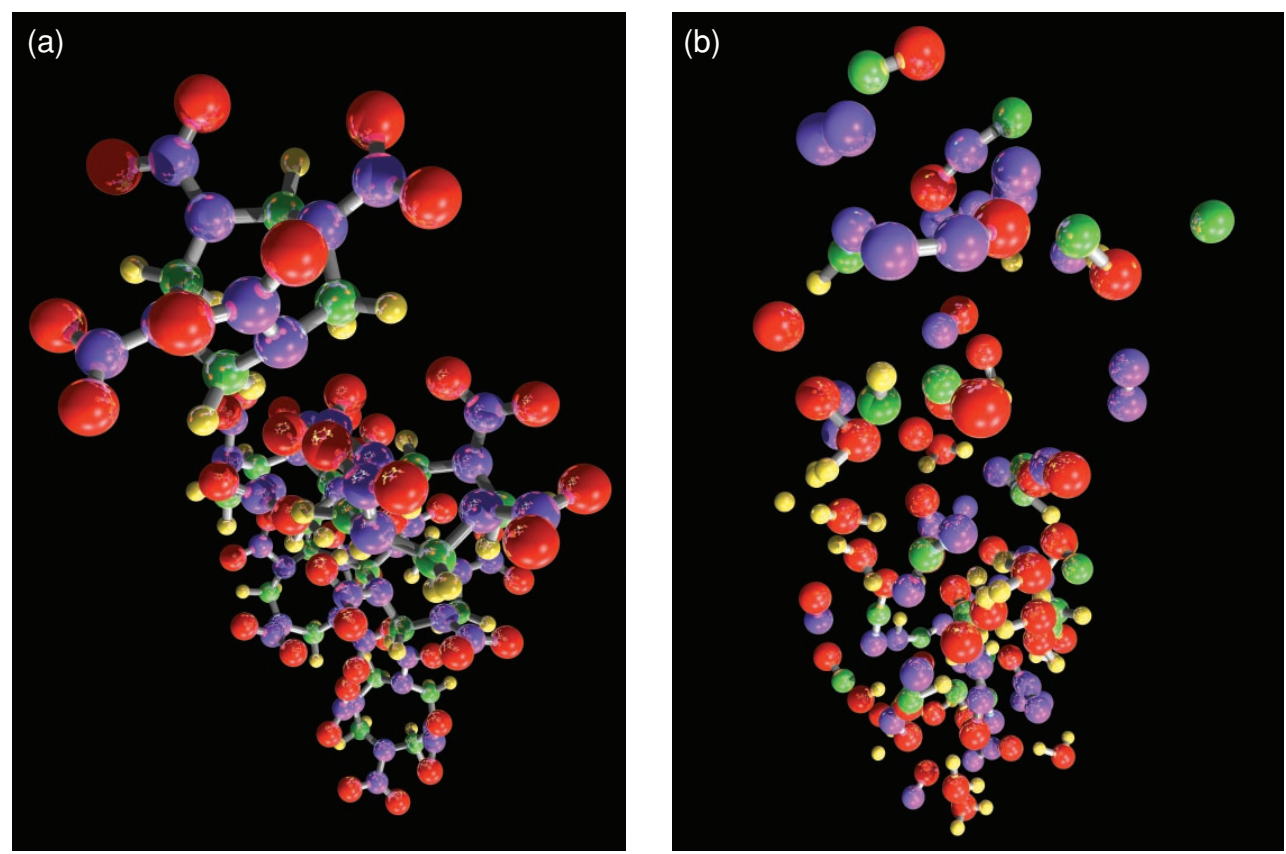

(a) A simulation of HMX under extreme conditions shows that stable molecules such as water form in less than 1 picosecond. (b) Slower chemical processes continue to change the chemical composition of HMX throughout the decomposition process.

These simulations showed how and in what order the molecules rearrange themselves as well as what intermediate products are formed.

At about $3,200^{\circ} \mathrm{C}$ and reaction times of up to 100 picoseconds, HMX decomposes through an initial step of nitro group elimination. Stable molecules such as water form rapidly - the first stable products appearing in less than 1 picosecond. But the transformation doesn't stop there. Slower chemical processes continue to change the chemical composition of HMX throughout the decomposition process. (See the figure above.)

According to chemist Joe Zaug, Livermore scientists are also beginning to examine in more detail the complex chemical systems on board weapon devices. "Moreover, the ultimate result of a detonated weapon is chemical species at extreme conditions," says Zaug. "If we can fully understand the behavior of a candidate species at relevant conditions, then we can work backward using the computational codes to better understand the detonation process."

\section{Beyond Stockpile Stewardship}

Understanding the stepwise changes that occur during these ultrafast reactions has far broader applications than high explosives. Data from HE experiments can be used to study the fundamental behavior of many materials under extreme conditions, from fossil fuels to water to the elements that form stars and planets.

One of these studies used laser-based ultrasonic technology to characterize iron, the main constituent of Earth's core. With this technique, the Livermore team recorded the precise sound velocity of iron under a pressure seven times greater than in previously reported experiments.

Other characterization techniques, which take less direct measurements, had led scientists to infer the makeup of Earth's internal structure, but those inferences were not borne out by the Livermore team's measurements. Instead, results indicate that the density of Earth's inner core is consistent with that of pure iron between 5,000 and $6,000^{\circ} \mathrm{C}$, and the liquid outer core is less dense than pure iron. Such data help scientists better understand phenomena such as the strength of Earth's magnetic field and, in turn, begin to answer related questions - for example, by determining the role of the magnetic field in protecting Earth from solar flares.

Other experiments performed with diamond anvil cells or gas guns can mimic conditions similar to the atmospheres of giant planets and the outer envelopes of low-mass stars composed mostly from hydrogen. Data from these experiments can then be used to characterize the composition and evolution of the giant planets.

For example, scientists have learned that Neptune and Uranus are rich in methane gas, which transforms to hydrogen and various hydrocarbons under extremely high pressures and temperatures. Indeed, researchers have suggested that the methane in large planets may conceivably turn into diamond at shallow depths, about one-tenth of the way to the center.

Nearly two decades ago, Nellis led a project that shocked cooled, compressed liquid methane. "Francis Ree then ran a chemical equilibrium calculation with our data," says Nellis. "His simulation showed that methane at these conditions produced diamond and molecular hydrogen. So we have reason to believe the cores of Neptune and Uranus are most likely made of diamond."

Nellis adds that the project's findings were a spin-off result from the Laboratory's weapons research, which routinely used the single-carbon molecule methane in place of real explosives. "Hydrocarbons such as methane are a simple way to test an HE detonation," says Nellis. "Real explosives are complex, and testing with simpler species helps us 


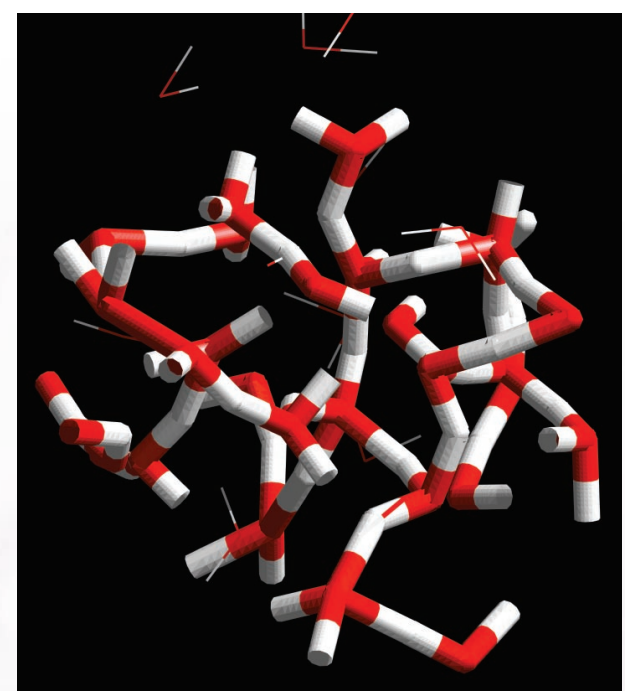

Applying extreme pressures and temperatures to water creates transient chains of oxygenhydrogen-oxygen $(\mathrm{O}-\mathrm{H}-\mathrm{O})$ molecules-a new phase of water.

understand the processes that occur during detonation." For example, some chemical reactions cause complex materials to rapidly decompose into simpler molecules, such as water, oxygen, nitrogen, carbon monoxide, and methane. The same reaction happens in giant planets.

"Uranus and Neptune are big balls of explosive materials," says Nellis. "Hydrogen accounts for 90 percent of all the atoms in the universe. The combination of hydrogen with oxygen gives us water, hydrogen with nitrogen gives us ammonia, and with carbon, we get methane. When all these accrete into one planet-collect in a snowballing effect - the planet gets bigger, and the materials deeper down are under even greater pressure. Because these materials are poor thermal conductors, the heat that's generated is trapped for millions of years, which leads to a very hot interior-much like the center of a detonated high explosive."

Fried's group also simulated water under high pressures and temperatures. In those calculations, the hydrogen atoms moved quickly, but the oxygen atoms were slower. As a result, short-lived transient chains of oxygen-hydrogen-oxygen $(\mathrm{O}-\mathrm{H}-\mathrm{O})$ were being continually created and broken. Because the $\mathrm{O}-\mathrm{H}$ bond is weak under these extreme conditions, the molecules exhibited a weak covalent character that is mostly ionic.

"We could say that we're turning water into salt by squeezing it really hard," says Fried. "What's important about our results is the information we acquire about the behavior of water under planetary conditions, which helps us better understand the magnetic properties of planets. We may find that the electrical conductivity of these molten salts is an important characteristic of giant planet interiors."

Extreme chemistry research has even challenged some of the most fundamental assumptions about the composition of fossil fuels. In 2003, a team of scientists from the Carnegie Institute of Washington re-created the conditions that exist more than 100 kilometers below Earth's surface.

The team compressed marble, iron oxide, and water at pressures about 50,000 times atmospheric pressure and at temperatures of about $1,500^{\circ} \mathrm{C}$. Those experiments produced methane, the main constituent of natural gas. When the Carnegie data were modeled with the CHEETAH code, the simulations indicated that near the Earth's mantlewhere temperatures and pressures are extremely elevated-petroleum may be forming inorganically.

\section{Is It All So Extreme?}

Hot outer planets, molten iron at the outer core of Earth, detonation processes-extreme conditions seem to be everywhere. But is it all really extreme? According to Zaug, the conditions at Earth's surface and within its delicate atmosphere are far from common. "The conditions we live under are unusual," says Zaug. "The conditions we create during so-called extreme chemistry experiments are not extreme-they're normal."

And as scientists learn more about the chemical reactions that can initiate a detonation sequence, they glimpse the balance of the universe.

-Maurina S. Sherman

Key Words: CHEETAH code, chemical kinetics, diamond anvil cell, equation of state, extreme chemistry, gas gun, high explosives (HE), planetary physics, shock physics, thermochemical code.

For further information contact Larry Fried (925) 422-7796 (fried1@IInl.gov). 


\section{Nuclear Energy to Go A Self-Contained, Portable Reactor}

N UCLEAR energy supplies 20 percent of the electricity used in the U.S. and 16 percent of that used throughout the world. But as the global use of nuclear energy grows, so do concerns about the vulnerability of nuclear plants and fuel materials to misuse or attacks by terrorists. A Livermore team is part of a Department of Energy (DOE) collaboration that is addressing both the growing need for nuclear energy and the concern over nuclear proliferation by pursuing a concept called SSTAR, a small, sealed, transportable, autonomous reactor.

SSTAR is designed to be a self-contained reactor in a tamperresistant container. The goal is to provide reliable and costeffective electricity, heat, and freshwater. The design could also be adapted to produce hydrogen for use as an alternative fuel for passenger cars.

Most commercial nuclear reactors are large light-water reactors (LWRs) designed to generate 1,000 megawatts electric (MWe) or more. Significant capital investments are required to build these reactors and manage the nuclear fuel cycle. Many developing countries do not need such large increments of electricity. They also do not have the large-scale energy infrastructure required to install conventional nuclear power plants or personnel trained to operate them. These countries could benefit from smaller energy systems, such as SSTAR, that use automated controls, require less maintenance work, and provide reliable power for as long as 30 years before needing refueling or replacement.

Many of the countries in need of nuclear energy are among the 187 nations that have signed the Non-Proliferation Treaty (NPT) enacted in 1970. Under the terms of this treaty, the five acknowledged nuclear-weapon states - the U.S., Russian Federation, United Kingdom, France, and China - agreed not to transfer nuclear weapons, other nuclear explosive devices, or related technology to those signatory states that have no nuclear weapons. These nonnuclear states agreed not to acquire or produce nuclear weapons or nuclear explosive devices, and in exchange, they have access to peaceful nuclear technology developed by the five nuclear signatories. Unfortunately, the NPT has some weaknesses, as demonstrated by the recent disagreements with Iran and North Korea. Although both countries had signed the NPT, their nuclear energy programs are not in keeping with their treaty agreements.

To address this problem, DOE is funding an initiative to develop a conceptual design of a reactor that will deliver nuclear energy

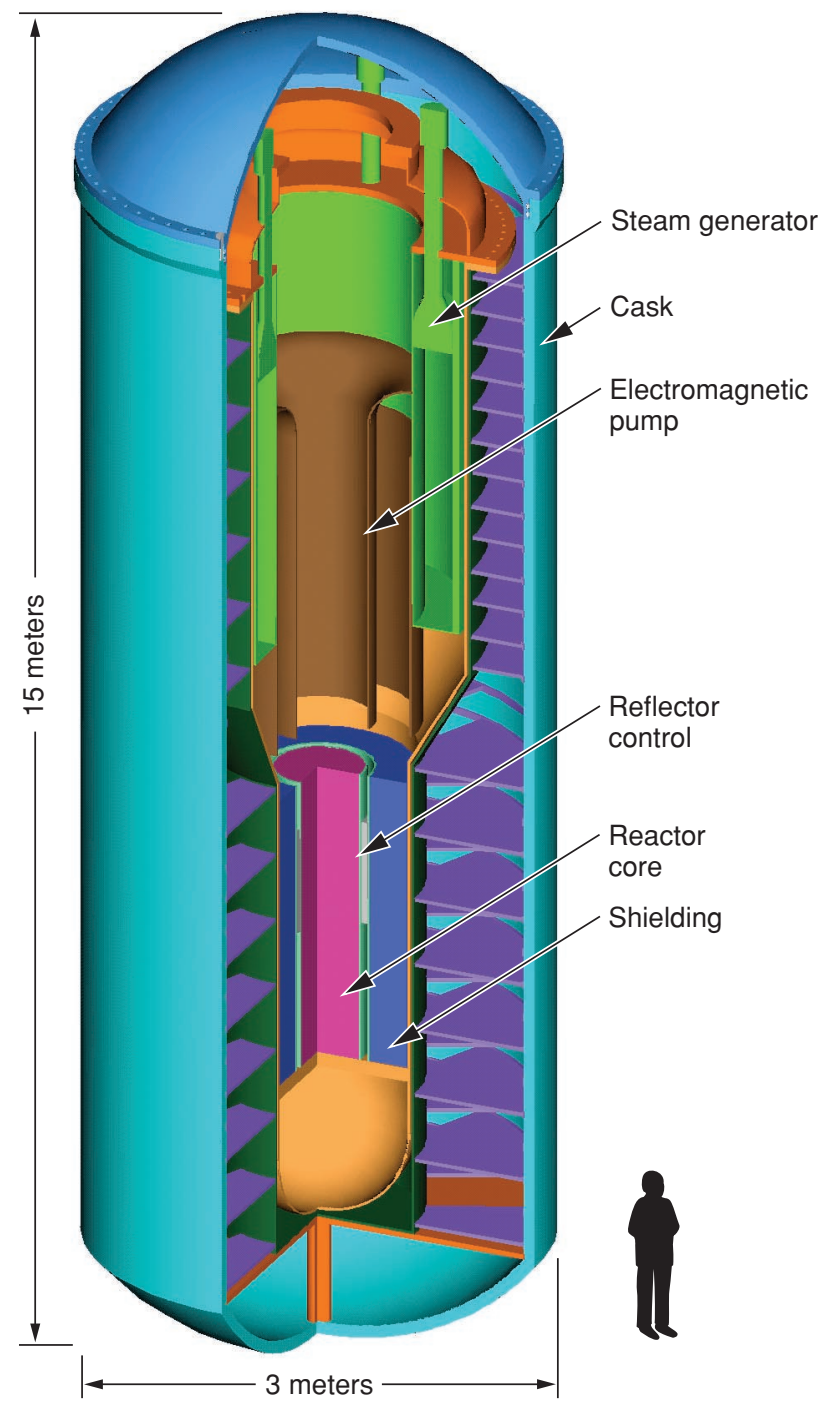

Lawrence Livermore, Los Alamos, and Argonne national laboratories are designing a self-contained nuclear reactor with tamper-resistant features. Called SSTAR (small, sealed, transportable, autonomous reactor), this next-generation reactor will produce 10 to 100 megawatts electric and can be safely transported on ship or by a heavy-haul transport truck. In this schematic of one conceptual design being considered, the reactor is enclosed in a transportation cask. 
to developing countries and significantly reduce the proliferation concern associated with expanded use of nuclear power. Three national laboratories are collaborating on this initiative. Lawrence Livermore, which leads the collaboration, is researching materials and coolants for the reactor and evaluating how it can be deployed. Argonne is designing the reactor, and Los Alamos is contributing its expertise on coolant and fuel technologies.

The SSTAR design will accomplish DOE's goals by allowing the U.S. to provide a tamper-resistant reactor to a nonnuclear state while still safeguarding the nation's sensitive nuclear technology. SSTAR will also secure the nuclear fuel because, after its operation, the sealed reactor will be returned to a secure recycling facility for refueling or maintenance.

Designed to be deployable anywhere in the world, SSTAR may also meet a national need. In the U.S., the Nuclear Regulatory Commission (NRC) oversees more than 100 nuclear power plants that were built during the 1960s and 1970s. SSTAR would provide a secure and cost-effective system to replace older nuclear reactors as well as aging fossil-fuel plants, particularly in an isolated location.

\section{One Size Fitting Many Needs}

SSTAR is designed as a lead-cooled fast reactor (LFR) that can supply 10 to $100 \mathrm{MWe}$ with a reactor system that can be transported in a shipping cask. Fast reactors typically use liquid metal coolants, such as lead, lead-bismuth, or sodium, instead of water. Neutron kinetic energy is about 250 kiloelectronvolts in LFRs - much greater than in LWRs, where the low mass of hydrogen in the water coolant slows neutron velocity and, thus, energy to about 0.025 to 0.05 electronvolt. With fast-moving neutrons, SSTAR could produce the fissile material it needs to fuel continued operation at the same time that it generates energy. Spent fuel in the form of uranium and plutonium would remain in the reactor to generate power for up to 30 years. The spent reactor would then be returned to a secure recycling facility to close the fuel cycle and to minimize the high-level wastes generated by nuclear reactors, thus reducing the space and infrastructure needed for the long-term storage of radioactive wastes. The concept for recycling is to have almost all of the waste burned in the reactor's core.

According to project leader Craig Smith, a nuclear engineer in Livermore's Energy and Environment Directorate, the reactor will be about 15 meters tall by 3 meters wide and will not weigh more than 500 tons - small and lightweight enough to be transported on a ship and by a heavy-haul transport truck. "With SSTAR, countries won't need a large nuclear reactor industry to benefit from nuclear energy," says Smith. "Because the supplier nation will provide both the reactor and the associated fuel-cycle services, the host nation can produce electricity without needing an independent supply of uranium or other fuel at the front end of the cycle. The host nation also won't have to dispose of the nuclear waste at the back end of the cycle."

In addition, the current SSTAR design reduces the potential for a terrorist to divert or misuse the nuclear materials and technology. Nuclear fuel will be contained within the sealed, tamper-resistant reactor vessel when it is shipped to its destination, and the spent reactor core will be returned to the supplier for recycling.

SSTAR addresses proliferation concerns with other features as well. No refueling is necessary during the reactor's operation, which eliminates access to and long-term storage of nuclear materials on-site. The design also includes detection and signaling systems to identify actions that threaten the security of the reactor. And because of the reactor's small size and its thermal and nuclear characteristics, the design can include a passive method to shut down and cool the reactor in response to hardware or control failures.

\section{Reduced Operating Costs}

SSTAR also offers potential cost reductions over conventional nuclear reactors. Using lead or lead-bismuth as a cooling material instead of water eliminates the large, high-pressure vessels and piping needed to contain the reactor coolant. The low pressure of the lead coolant also allows for a more compact reactor because the steam generator can be incorporated into the reactor vessel. Plus with no refueling downtime and no spent fuel rods to be managed, the reactor can produce energy continuously and with fewer personnel.

SSTAR may also reduce costs for the transportation industry by providing a cheaper source of fuel to power passenger cars. Because LFRs can potentially operate at high temperatures (up to about $800^{\circ} \mathrm{C}$ ), the reactor can be used to generate the heat required for efficient production of hydrogen, which is the preferred fuel for fuel-cell vehicles and hybrid vehicles burning hydrogen in an internal combustion engine. (See $S \& T R$, June 2003, pp. 24-26.) As

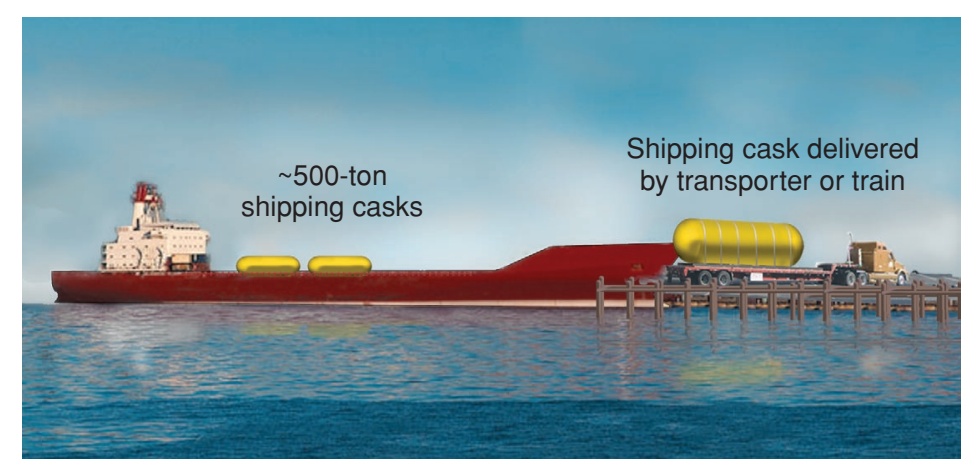

When it is upright, SSTAR will be about 15 meters high and 3 meters wide, and its total weight will not exceed 500 tons. This compact size will allow the nuclear reactor to be transported on a ship and by a heavy-haul transport truck. 
oil production becomes more expensive and constraints on carbon dioxide emissions tighten, the search for alternatives to fossil fuels becomes more important. SSTAR has the potential to address a critical national and international need for the future.

\section{Tackling the Design Challenges}

Several challenges must be addressed before the SSTAR design is ready for prototype testing. The Livermore team must develop materials for the fuel and coolant boundary that are compatible with the coolant. Lead, especially when alloyed with bismuth, tends to corrode the fuel cladding and structural steel. Controlling the oxygen in the coolant will help reduce corrosion. In addition, the team must identify materials that would best withstand the damaging effects of long-term exposure to fast neutrons. Structural damage could include material swelling and ductility loss, both of which may limit the life of the reactor.

In 2003, the Laboratory's SSTAR team participated in a feasibility study with a team from the Central Research Institute for Electric Power Industry (CRIEPI) in Japan. In this study, the two teams evaluated a modified design, developed by the Japanese team, for a small liquid metal-cooled reactor using sodium as a coolant. A scientist from CRIEPI is now working at Livermore, and the teams are sharing the results from their respective projects.

Passive safety features also will be developed to ensure that any failure in the control system will shut down the reactor and initiate a natural convection system to cool the reactor core and reactor vessel. The characteristics of these features will depend on the geometry and mechanical support system provided for the nuclear reactor. In addition, the prototype will test the performance of the passive safety features and the system designed to monitor them.

Because the spent reactor will be radioactive, the research team must develop packaging and transportation systems so the reactor can be removed safely. The team also must design a process to cool the reactor while it is being shipped to the recycling facility. The design criteria for meeting these challenges may affect the maximum power level that can be achieved.

\section{License-by-Test Certification}

NRC plans to certify the SSTAR design using a new licenseby-test approach, rather than the license-by-design approach that it used to certify most of the existing commercial nuclear power plants. NRC's license-by-test process is similar to the certification process used by the U.S. Federal Aviation Administration for commercial airliners. To be certified, the SSTAR prototype must demonstrate in a test environment that it can safely withstand accidents, including the most improbable ones such as failure of the active shutdown and shutdown heat-removal systems.

But the tri-laboratory collaboration has more work to do before an SSTAR demonstration. According to Smith, the team plans to refine the SSTAR design and then develop a prototype reactor, which could be ready for testing as early as 2015 . The Livermore team feels confident that SSTAR will provide a new-generation reactor-one that is safe, proliferation-resistant, and able to operate anywhere in the world.

-Gabriele Rennie

Key Words: Central Research Institute for Electric Power Industry (CRIEPI); lead-cooled fast reactor (LFR); Non-Proliferation Treaty (NPT); nuclear reactor; small, sealed, transportable, autonomous reactor (SSTAR).

For further information contact Craig Smith (925) 423-1772 (smith94@IInl.gov). 


\section{This Instrument Keeps the Beat}

A S part of their responsibilities for stewardship of the nation's nuclear stockpile, Livermore researchers study the behavior of materials detonated with high explosives or struck with projectiles at extreme velocities. In diagnosing these experiments, researchers must measure velocities as great as 3,000 meters per second over distances from less than 0.5 millimeter to more than 50 millimeters.

The ability to measure continually changing velocities is important. Within a few microseconds, shock waves cause objects, especially metal samples shocked by high explosives, to accelerate, decelerate, and then accelerate again. Precise velocity data gathered from experiments are used to refine the computer codes that model weapons physics. These data are especially important for improving the hydrodynamics codes used to simulate materials under the extreme pressures and temperatures generated by a highexplosives shock, when metals seem to flow as if they were liquid.

Livermore's Advanced Diagnostics Group, part of the Defense and Nuclear Technologies Directorate, is tasked with diagnosing hydrodynamics tests and other experiments that shock materials. To characterize these experiments, researchers use radiation detectors, imaging cameras, temperature probes, and velocimeters. They are continually in search of better diagnostic equipment to measure the extreme velocities. One recent Livermore development is a costeffective and easy-to-operate technique called the photonic Doppler velocimeter (PDV). (See the figure at right.) Equipped with two new telecommunication devices, the PDV takes advantage of a basic phenomenon that's taught in high school physics - the beat frequency.

\section{Making Use of Doppler Shift}

One method to determine the velocity of a moving surface is to measure the Doppler-shifted frequency of light reflected off that surface. The Doppler shift is the difference between the frequency at which sound or light waves leave a source and the frequency seen by an observer. The difference is caused by the relative motion of the observer and the source. A well-known example of the Doppler shift from sound waves is the falling pitch of a train as it moves away from a stationary observer.

This same relationship occurs with light waves. If laser light is shone on a stationary metal surface, light reflected from the surface will have the same frequency, or color, as the incident laser light. However, if the surface is moving, the Doppler shift slightly

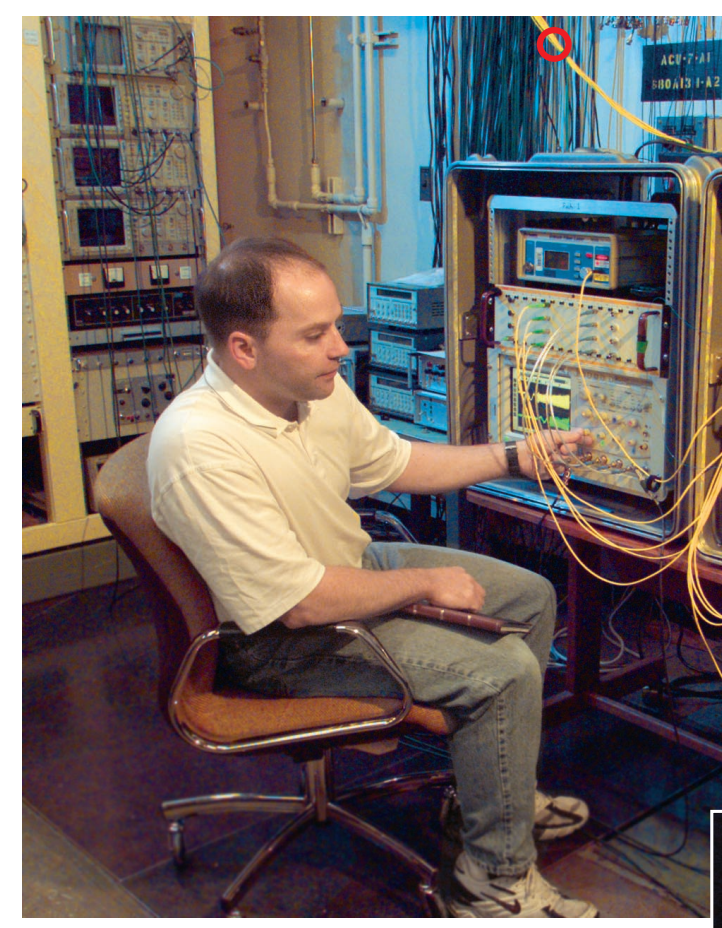

Laser technician Tony Whitworth adjusts the settings on the digitizer component of the photonic Doppler velocimeter (PDV). The PDV consists of a fiber laser, a detector chassis, and a digitizer with 20-gigahertz sample oscilloscopes. In this setup, the laser light is split into seven beams, with four feeding a detector and digitizer, and another three feeding a second detector and digitizer. The yellow optical fibers at the top of the case (see inset) are routed to an adjoining room and secured to the back end of a target assembly. In the experiment, a projectile from a gas gun hits a sample of aluminum placed on the opposite side of the target assembly. 
changes the frequency (color) of the reflected light. As the surface moves, the shift in frequency of the reflected light is proportional to the change in velocity of the illuminated surface. The greater the velocity, the greater the Doppler shift and frequency change.

Livermore researchers use several types of velocimeters that measure the Doppler effect. The most sophisticated is the multibeam Fabry-Perot velocimeter, developed in the mid-1990s by physicist David Goosman, who leads the Advanced Diagnostics Group. This device splits a laser light into five individual beams with very high efficiency, and five streak cameras then record the reflected laser light. In this way, the time history of material at five different spots on a metal's surface is recorded with extreme accuracy. (See $S \& T R$, July 1996, pp. 12-19.)

"The multibeam Fabry-Perot is a robust system that really tells us what is going on," says Livermore physicist Ted Strand, who also is a member of the Advanced Diagnostics Group. Unfortunately, the Fabry-Perot instrument must be custom manufactured, it takes up a lot of space, and several people are needed to operate it - all of which limit the number of channels that can be fielded on an experiment. In addition, many experimenters cannot afford to build a Fabry-Perot system.

Another diagnostic system, the commercially available VISAR (Velocity Interferometer System for Any Reflector), is less expensive than the Fabry-Perot and performs well for measuring a single velocity. However, a VISAR is inadequate for many of the experiments that could potentially produce multiple velocity signatures.

To overcome these problems, Strand searched for a more cost-effective method to measure velocity - one that would offer about the same accuracy as Fabry-Perot. That search led him to the beat frequency.

\section{Beat Frequency a Matter of Subtraction}

The beat frequency is the difference in frequency between two waves. It is easily evident in sound waves: Strike two tuning forks, each tuned to a slightly different frequency. The sound from the two forks will go up and down in volume rather slowly. In a similar manner, two guitar strings tuned almost identically and struck at the same time will also produce a beat frequency identified by an up-and-down volume. The "beats" are caused by the constructive interference, or combined amplitude, of two different waves as they pass the same point_-in these examples, the listener's ear. When the two waves are in phase, their combined amplitude is larger - or the noise is louder - than it is when the waves are out of phase.

The PDV detects the beat frequency from two slightly different frequencies of light by shining laser light at 1,550-nanometer wavelength (in the infrared spectrum) on the surface of a moving target. The Doppler-shifted laser light reflected off the target surface is collected and sent to a detector. At the same time, some of the original light is sent back to the same detector. The incident laser light has a frequency of $1.93 \times 10^{14}$ hertz, or $193,414.49$ gigahertz. If the target is moving at 1,000 meters per second, the Doppler-shifted laser light will have a frequency of 193,415.78 gigahertz. Both frequencies are so rapid that no existing detector can directly measure them. However, high-speed detectors can measure the difference in frequencies - the beat frequency because it is much slower than either the original laser light or the Doppler-shifted light.

In this example, the beat frequency measures 1.29 gigahertz, or less than 1/200,000 of the original frequency. "Once we know the beat frequency," says Strand, "we can infer the velocity of the metal surface. Then we have data to construct a graph of velocity versus time."

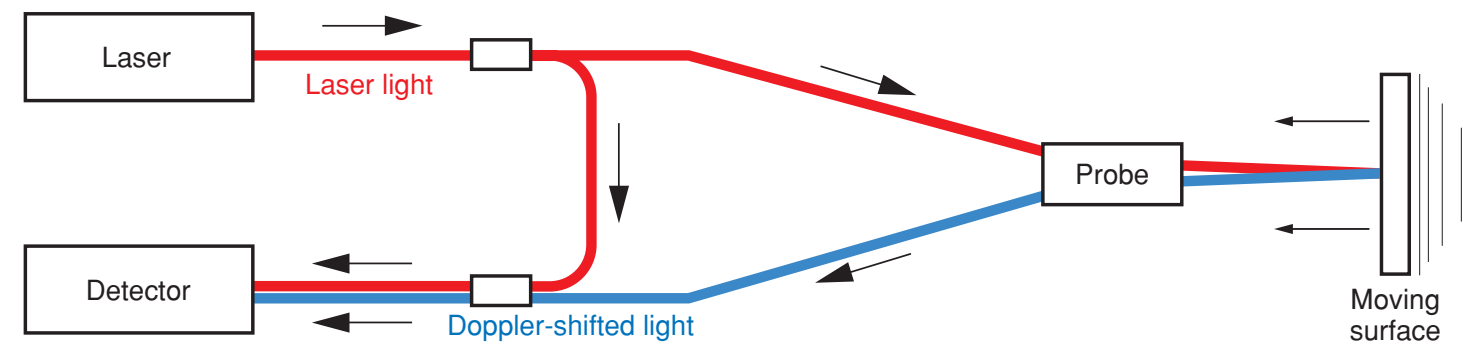

The photonic Doppler velocimeter detects the beat frequency between two slightly different frequencies of light. Laser light (red) from a probe is shone on a moving surface. The Doppler-shifted light (blue) is collected and sent to a detector. At the same time, some of the original light is sent to the same detector. The difference in frequency between the two-the beat frequency-is much slower than either the original laser light or the Doppler-shifted light, allowing researchers to infer the velocity of the metal surface and construct a graph of velocity versus time. 
Goosman had once considered using the beat frequency as the basis for a velocimeter, but developing such an instrument for an explosive experiment was impractical until about a year ago. That's when Strand noticed two new and relatively inexpensive telecommunication devices: an extremely fast digitizer and a compact fiber laser.

The digitizer used in the PDV can measure 20 billion samples per second. "That's an extraordinary sampling rate, but it's just barely fast enough to follow an exploding metal sample," says

(a)
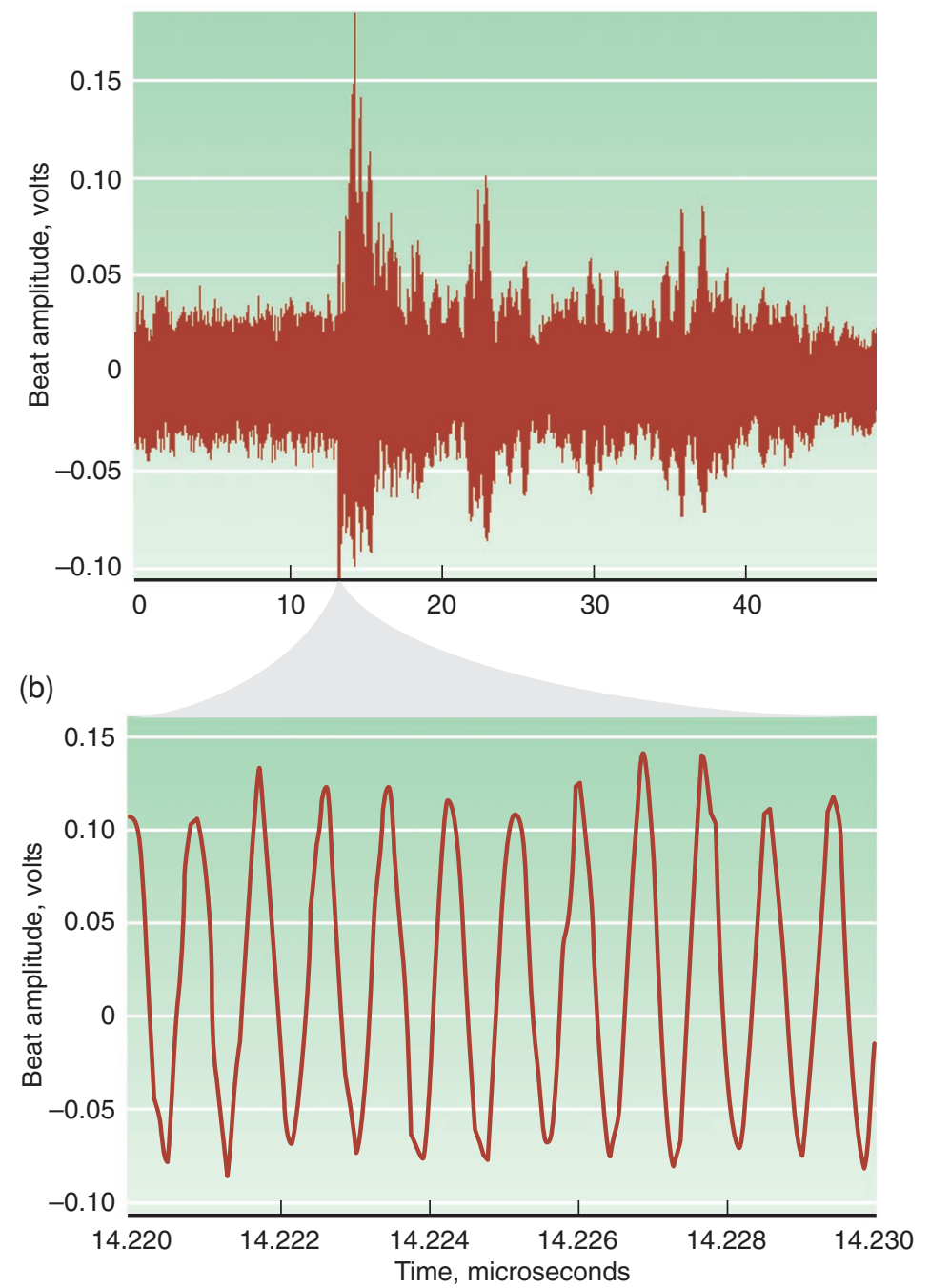

(a) This example shows the beat frequency (converted to amplitude) recorded during 50 microseconds of a high-explosive experiment. (b) The waves from a 10-nanosecond period of the beat frequency are extracted from (a).
Strand. The 20-gigahertz sampling rate generates 1 million data points in a 50-microsecond experiment, which is fast enough to provide at least 4 data points for every recorded beat-frequency wave. (See the figure below.)

\section{Fiber Laser Keeps Things Simple}

Another telecommunications product featured in the PDV is compact and affordable high-power fiber lasers. The optical fibers in these lasers, which have 9-micrometer-diameter cores, are doped with rare-earth metals to amplify the laser light. In addition, the laser power can be adjusted over a broad range. Livermore researchers use light of 1,550-nanometer wavelength because that wavelength is used by the telecommunications industry. "The fiber becomes the laser," says Strand. "This design does away with a lot of optics and other components that traditional lasers require."

In the PDV, the originating laser light can be split into as few as four beams or as many as eight. The four to eight fibers deliver light from the control room out to the experiment area, where they have been placed between a few millimeters to 25 centimeters away from the target. During the fleeting experiment, some of the reflected light returns to the control room on these same fibers. The reflected light and a sample of the original light are converted to an electrical signal. This beat signal is then amplified and digitized.

The PDV has been used in more than 20 experiments conducted at Livermore's remote experimental site and its High Explosives Applications Facility. It has also been used at the Big Explosives Experimental Facility, located at the Nevada Test Site (NTS). Plans are under way to use the diagnostic at the underground U1a complex, also at NTS, where subcritical experiments involving small amounts of plutonium are performed. Tests conducted in April 2004 at Livermore's small gas-gun facility demonstrated that PDV would be a valuable diagnostic at JASPER - the much larger Joint Actinide Shock Physics Experimental Research Facility gas gun at NTS. (See $S \& T R$, June 2004, pp. 4-12.)

PDV is promising to become a standard element in the arsenal of diagnostic techniques available to Livermore researchers. Commercial products make the technique easy to set up, simple to operate, and cost effective. If the early successes are any indication, more Livermore experiments will focus on the beat.

- Arnie Heller

Key Words: beat frequency, Fabry-Perot velocimeter, fiber laser, photonic Doppler velocimeter (PDV).

\section{For further information contact Ted Strand (925) 423-2062 (otstrand@IInl.gov).}




\section{Patents}

Reduction of Damage Initiation Density in Fused Silica Optics Via UV Laser Conditioning

John E. Peterson, Stephen M. Maricle, Raymond M. Brusasco, Bernardino M. Penetrante

U.S. Patent $6,705,125$ B2

March 16, 2004

This invention provides a method for reducing the density of sites on the surface of fused silica optics that are prone to laser-induced damage. As a result, optics have far fewer catastrophic defects and can better resist optical deterioration when exposed for a long time period to a high-power laser beam with a wavelength of about 360 nanometers or less. The initiation of laser-induced damage is reduced by conditioning the optic at fluences below those levels that normally lead to catastrophic growth or damage. When the optic is then irradiated at its high fluence design limit, the concentration of catastrophic damage sites that form on the optic surface is greatly reduced.

Cylindrical Microlens with an Internally Reflecting Surface and a Method of Fabrication

Raymond J. Beach, Barry L. Freitas

U.S. Patent $6,710,926$ B2

March 23, 2004

A fast (high-numerical-aperture) cylindrical microlens, which includes an internally reflective surface, deviates the direction of the light entering the lens from its original propagation direction. This microlens is used in optically conditioning laser diodes, laser-diode arrays, and laserdiode bars.

System and Method for Characterizing Voiced Excitations of Speech and Acoustic Signals, Removing Acoustic Noise from Speech, and Synthesizing Speech

\section{Greg C. Burnett, John F. Holzrichter, Lawrence C. Ng}

U.S. Patent $6,711,539$ B2

March 23, 2004

This invention is a system and method for characterizing human (or animate) speech voiced excitation functions and acoustic signals, for removing unwanted acoustic noise that often occurs when a speaker uses a microphone in common environments, and for synthesizing personalized or modified human (or other animate) speech on command from a controller. A low-power electromagnetic (EM) sensor is used to detect the motions of windpipe tissues in the glottal region of the human speech system before, during, and after voiced speech is produced by a user. A voiced excitation function can be derived from these tissue motion measurements. The excitation function also provides speech production information to enhance noise removal from human speech, and it enables accurate transfer functions of speech to be obtained. Previously stored excitation and transfer functions can be used for synthesizing personalized or modified human speech. Configurations of EM sensor and acoustic microphone systems are described to enhance noise cancellation and to enable multiple articulator measurements.
Inorganic Metal Oxide/Organic Polymer Nanocomposites and Method Thereof

Alexander E. Gash, Joe H. Satcher, Randy Simpson

U.S. Patent $6,712,917$ B2

March 30, 2004

This synthetic method for preparing hybrid inorganic and organic energetic nanocomposites uses stable metal inorganic salts, organic solvents, and an organic polymer with good solubility to produce novel nanocomposite energetic materials. Fuel metal powders, particularly those that are oxophillic, can also be added to the composition. These materials have been characterized by thermal methods, energy-filtered transmission electron microscopy, adsorption and desorption methods, and Fouriertransform infrared spectroscopy. The characterization results indicate that the organic polymer phase fills the nanopores of the composite material, providing superb mixing of the component phases in the energetic nanocomposite.

\section{Microchannel Cross Load Array with Dense Parallel Input Stefan P. Swierkowski \\ U.S. Patent 6,716,328 B1 \\ April 6, 2004}

An architecture or layout for microchannel arrays uses T or cross (+) loading for electrophoresis or other injection and separation chemistry performed in microfluidic configurations. This architecture enables a dense layout of arrays of functionally identical shaped channels, and it solves the problem of simultaneously enabling efficient parallel shapes and biasing of the input wells, waste wells, and bias wells at the input end of the separation columns. One T-load architecture uses circular holes with common rows, but not columns, so the flow paths for each channel are identical in shape, using multiple mirror image pieces. Another T-load architecture enables the access hole array to be formed on a biaxial, collinear grid suitable for electrical discharge micromachining (square holes) with common rows and columns.

Programmable Phase Plate for Tool Modification in Laser Machining Applications

Charles A. Thompson, Jr., Michael W. Kartz, James M. Brase, Deanna Pennington, Michael D. Perry

U.S. Patent $6,717,104$ B2

April 6, 2004

This system for laser machining includes a laser source for propagating a laser beam toward a target location and a spatial light modulator with individual controllable elements. The system can thus modify a phase profile of the laser beam to produce a corresponding irradiance pattern on the target location. The system also includes a controller, operably connected to the spatial light modulator, for manipulating the individual controllable elements. When these elements are controlled, the phase profile of the laser beam may be modified as desired to produce a corresponding irradiance pattern on the target location, thus allowing a machining operation to be performed on the target location. 
Fibers and Fabrics with Insulating, Water-Proofing, and FlameResistant Properties

Lawrence W. Hrubesh, John F. Poco, Paul R. Coronado

U.S. Patent $6,723,378$ B2

April 20, 2004

Fibers and fabrics produced from the fibers are made water repellent, fire retardant, or thermally insulating by filling void spaces in the fibers or fabrics with a powdered material. When the powder is sufficiently finely divided, it clings tenaciously to the fabric's fiber and to itself, resisting the tendency to be removed from the fabric.

Femtosecond Laser-Electron X-Ray Source

Frederic V. Hartemann, Hector A. Baldis, Chris P. J. Barty,

David J. Gibson, Bernhard Rupp

U.S. Patent 6,724,782 B2

April 20, 2004

This femtosecond laser-electron x-ray source includes a highintracavity-power, mode-locked laser and an x-ray optics system. A high-brightness relativistic electron injector produces an electron-beam pulse train. A system then accelerates the pulse train.

Ultrashort-Pulse Laser Machining System Employing a

Parametric Amplifier

Michael D. Perry

U.S. Patent $6,728,273$ B2

April 27, 2004

A method and apparatus are provided for increasing the energy of chirped laser pulses to an output ranging from 0.001 to more than 10 millijoules at a repetition rate of 0.010 to 100 kilohertz. A two-stage optical parametric amplifier is used with a bulk nonlinear crystal so the pump and signal beam size can be independently adjusted in each stage.

Three Dimensional Separation Trap Based on Dielectrophoresis and Use Thereof

Raymond P. Mariella, Jr.

U.S. Patent $6,730,204$ B2

May 4, 2004

An apparatus is adapted to separate target materials from other materials in a flow that contains both. A dielectrophoretic trap with at least one electrode system is adapted to receive the materials. The electrode system has a three-dimensional configuration that includes a first and second electrode. The two electrodes are shaped and positioned so that an electrical voltage applied to them creates a dielectrophoretic force that does not reach zero between the two electrodes.

\section{Magnetohydrodynamic (MHD) Driven Droplet Mixer \\ Abraham P. Lee, Asuncion V. Lemoff, Robin R. Miles}

U.S. Patent $6,733,172$ B2

May 11, 2004

A magnetohydrodynamic fluidic system with three substrate sections mixes two substances. Each substrate section includes a flow channel with a plurality of pairs of spaced electrodes connected to it. A magnetic section and a control section are then connected to the spaced electrodes. The mixer moves two substances - one through the first flow channel and another through the second flow channel-into the third flow channel, where they are mixed.

\section{Stable Glow Discharge Detector \\ Jackson C. Koo, Conrad M. Yu}

U.S. Patent 6,736,000 B2

May 18, 2004

A highly sensitive electronic ion cell uses glow discharge to measure trace elements in a helium carrier gas. A constant wave stable glow discharge detector, which is controlled through a biased resistor, can detect the change of electron density caused by impurities in the helium carrier gas by many orders of magnitude larger than that caused by direct ionization or electron capture. The detector uses a floating pseudo-electrode to form a probe in or near the plasma and a solid rod electrode. This probe directly measures the large variation of electron density due to trace amounts of impurities. The solid rod electrode provides greater stability and thus easier alignment.

Wireless, Relative-Motion Computer Input Device John F. Holzrichter, Erwin T. Rosenbury

U.S. Patent 6,738,044 B2

May 18, 2004

This invention provides a system for controlling a computer display in a workspace using an input unit and output unit. Electromagnetic (EM) waves are sent to flood the workspace and are reflected from the input and output units. A relative-distance-moved information signal is created using the reflected EM waves. Algorithms convert this signal to a display signal, which controls the computer display. 


\section{Awards}

Livermore researchers Edmond Chow and Christine Orme each received a 2002 Presidential Early Career Award for Scientists and Engineers - the highest honor bestowed by the U.S. government on scientists and engineers who, early in their careers, show exceptional potential for leadership at the frontiers of knowledge. Chow, a computer scientist in the Laboratory's Computation Directorate, was honored "for research into preconditioning methods for discretized partial differential equations that has enabled scientists at LLNL to perform implicit simulations that were previously impossible. His planned research will produce still more sophisticated techniques; these will greatly facilitate the manner in which numerical simulation methods are developed and applied." Orme, a physicist in the Chemistry and Materials Science Directorate, was honored "for her work in understanding the physical mechanisms of biomineralization and the development of force microscopy-based methods of investigating mineralization at the nanoscale."

Livermore postdoctoral researcher Richard Snavely received the Allen G. Marr Distinguished Dissertation Award from the University of California (UC) at Davis for his dissertation, "Physics of Laser Driven Relativistic Plasmas, Energetic X-Rays, Proton Beams and Relativistic Electron Transport in Petawatt Laser Experiments." The award is given annually in honor of Allen G. Marr, Dean of Graduate Studies and Research, to a current or past UC Davis doctoral student for superior dissertation work that "makes an unusually significant contribution to the discipline." Snavely, a former Student Employee Graduate Research Fellowship student, works in the National Ignition Facility's High Energy Density Experimental Science Program.

Chemical Abstracts Service (CAS), a division of the American Chemical Society, selected a paper written by a team of researchers from Lawrence Livermore and the U.S. Army Dugway Proving Grounds' West Desert Test Center as the most intriguing paper of the fourth quarter of 2003. The team's article, which appeared in the October 15, 2003, issue of Analytical Chemistry, details the use of the Autonomous Pathogen Detection System (APDS) - the Laboratory's next-generation biological detection system. It was chosen from about 200,000 documents reviewed by CAS. The paper's coauthors are Don Masquelier, Steve Brown, Thomas Metz, and Keith Burris (now retired) from Livermore's Engineering Directorate; Benjamin Hindson, Anthony Makarewicz, Kodumudi Venkateswaran, and Bill Colston from the Physics and Advanced Technologies Directorate; Fred Milanovich, founder of the Laboratory's Chemical and Biological National Security Program; Richard Langlois from the Biology and Biotechnology Research Program; and Kar Wing Tsang, Ruth Bryan, and Doug Anderson from the West Desert Test Center in Dugway, Utah.

\section{The National Nuclear Security Administration} (NNSA) honored 10 Lawrence Livermore firefighters for their heroic actions in fighting two wildfires in southern California. In October 2003, the Laboratory dispatched 3 strike teams and 10 firefighters to assist the crews battling the Grand Prix fire in San Bernardino County and the Cedar fire in San Diego County. The firefighters were honored for their "expertise, dedication and professionalism" in saving "numerous homes, structures and property" from the largest wildfire in California history. "Their heroic actions have brought great credit to the Department of Energy and Lawrence Livermore National Laboratory," said NNSA Administrator Linton Brooks, in the inscription on each award. The honorees were battalion chiefs James Watkins and Mike Mclaughlin, captains Randy Carter and Robert Verdie, and firefighters Stephen Keating, Cindy Mariolle, Mike Moyles, Matt Portteus, Ken Rinna, and Kyle Willet.

Patricia Axelrod was selected Outstanding Chairperson of 2003 by the San Francisco/East Bay Branch of Community Health Charities of California (CHCC) for her work as cochair of the Laboratory's 2003 HOME (Helping Others More Effectively) campaign. Axelrod was chosen because of her enthusiasm and focus in arranging presentations for Livermore employees so they could learn more about the charities participating in the campaign. CHCC supports the California chapters of more than 50 national and regional health agencies. The 2003 HOME campaign raised more than $\$ 1.5$ million for more than 200 nonprofit agencies.

Jose M. Hernandez was selected by the National Aeronautics and Space Administration (NASA) to join the 2004 Astronaut Candidate Class. Hernandez worked as an electrical engineer at Livermore for 15 years before taking a leave of absence in 2001 to join NASA. 


\section{Helping Water Managers Ensure Clean and Reliable Supplies}

Livermore researchers are working on a three-part initiative designed to help California water managers make important decisions about safeguarding the supplies and quality of public drinking water. California's water situation is precarious because underground aquifers are being consumed at an increasing rate and contaminants and changing patterns in rain and snowfall are threatening the adequacy of supplies. The first project links climate and surface hydrology models running on supercomputers to address the effects of climate change and variability on the supply of freshwater in the coming decades. The second project studies ways to better understand and manage nitrate, the leading contaminant of California groundwater. The third project focuses on treating contaminated water with new, cost-effective membranes for electrodialysis. The initiative is managed by the Energy and Environment Directorate and uses Livermore expertise in chemistry and materials science, environmental science, microbiology, and computer modeling.

\section{Contact:}

Robin Newmark (925) 423-3644 (newmark1@IInl.gov).

\section{Going to Extremes}

Scientists in the Laboratory's Extreme Chemistry Group are studying the chemical reactions that occur at extreme conditions, such as those near Earth's core and in high-explosive reactions and impacts from meteorites and comets. Their work is a critical research area for scientists who support the nation's Stockpile Stewardship Program. It provides more accurate data on the optical, mechanical, and energetic properties of weapon materials throughout the detonation process. When an element is exposed to intense pressures and temperatures - up to one million times the atmospheric pressure at Earth's surface and above $6,000^{\circ} \mathrm{C}$-its fundamental properties can completely change. In fact, its atoms can rearrange themselves, rendering an entirely new substance. By better understanding these chemical reactions, scientists can improve the simulation codes used to predict the performance of weapons in the nation's nuclear stockpile. The group's research also applies to emerging technologies in nanoscale and energetic materials.

\section{Contact:}

Larry Fried (925) 422-7796 (fried1@IInl.gov).

\section{Datorting Hididen Iucloar Matorials}

The Radiation Detection Center helps researchers develop new technology for national security and basic science programs.

\section{Also in September}

- Compact, low-cost micropower radar and communication systems that use ultrawideband frequencies are strengthening national security and changing commercial markets.

- A solid-state modulator system designed by Livermore replaces vacuum-tube devices in the proposed Next Linear Collider.

- Livermore scientists shift their focus from the study of individual genes to entire biological systems. 
